\title{
The Potential of Wind Energy and Design Implications on Wind Farms in Saudi Arabia
}

\author{
Muhammad Tayyab Naqash ${ }^{a^{*}}$, Mohammad Hasan Aburamadana, Ouahid Harirechea, \\ Abdulrahman AlKassem ${ }^{b}$, Qazi Umar Farooqa
}

aDepartment of Civil Engineering, Faculty of Engineering, Islamic University in Madinah, Saudi Arabia

${ }^{b}$ Department of Electrical Engineering, Faculty of Engineering, Islamic University in Madinah, Saudi Arabia

\begin{abstract}
Climate change and natural resource depletion are likely to affect the future economic development of a country. The generation of power from oil and gas is among the major causes of reserves depletion and global warming. However, renewable energy is also deemed a clean and green choice for power generation to promote sustainability in engineering. The coastal lines of the Kingdom of Saudi Arabia (KSA) are widely extended, and wind energy appears to be a viable alternative to traditional sources, which needs to be investigated as it is highly desirable to seek energy from renewable energy sources, for instance, wind. This paper is aimed at addressing the wind energy potential along the Red Sea coast of KSA. Afterward, a suitable wind turbine based upon careful structural analysis has been proposed, which would form a basis, especially during the machine selection and design phases. For this purpose, seven different sites located along the coastal line, namely: Al Wajh, Umluj, Yanbu, Rabigh, Jeddah, Haddad, and Gizan, were initially selected to assess the wind energy availability. After that, a suitable turbine is recommended for yielding maximum output. It has been found from the reconnaissance that $\mathrm{Al}$ Wajh has sufficient land availability that receives high perennial wind speed, alongside shallow offshore water depth for monopile installation. Hence, this site is recommended for the development of a wind farm. Furthermore, turbines need to be installed at the height of almost $100 \mathrm{~m}$ to produce maximum energy to appropriately utilize the available indigenous wind energy. It is pertinent to mention that the superstructure of the turbines is designed based on the local loading conditions (wind, currents, waves, etc.) of the $\mathrm{Al}$ Wajh region. Also, the monopile substructures are proposed in the selected area in accordance with the available bathymetry.
\end{abstract}

Keywords: renewable energy, monopile, wind energy, wind load, waves, currents, offshore structures, hub height, RETscreen, wind maps

Article History: Received: 4th May 2021; Revised: 20th JNune 2021; Accepted: 28 th Nune 2021; Available online: $10^{\text {th }}$ July 2021

How to Cite This Article: Naqash, M.T., Aburamadan, M.H., Harireche, O., AlKassem, A., Farooq, Q.U. (2021). The Potential of Wind Energy and Design Implications on Wind Farms in Saudi Arabia. Int Journal of Renewable Energy Development, 10(4), 839-856

https://doi.org/10.14710/ijred.2021.38238

\section{Introduction}

Wind energy is sustainable and is a growing form of alternative energy, that inhibits pollution and a variety of atmospheric emissions, which could lead to acid rain, smog, or greenhouse gases, among others. The Kingdom of Saudi Arabia (KSA) has vast open land and an outstanding potential to use renewable energy sources, such as solar and wind. This so-called clean energy tends to gradually become a substitute to current energy sources, such that fossil fuels are employed on widescale and in large proportions both in domestic and industrial sectors. It suggests that wind farms can be an attractive technology of renewable energy across KSA. The wind power potential is expected to plummet the national energy demand that is usually fulfilled by oil and gas. Moreover, KSA is developing rapidly with the Government's vision of attaining the milestone of a developed nation by 2030 . However, till then, the domestic consumption of energy would unfortunately be almost threefold.
Nonetheless, no competitive renewable energy sector exists in KSA (Kingdom of Saudi Arabia \& Saudi Vision 2030, 2016). Therefore, as part of the Government's plan to develop renewable energy and reduce the dependence on crude oil and natural gas, a target has been set to generate $9.5 \mathrm{GW}$ of power from renewable sources by 2023 . The worldwide promotion of wind power utilization is mainly attributed to the enormous development in the wind industry and the availability of massive wind turbines. However, installation of the huge wind turbines is challenging due to structural safety and other issues. Therefore, several design alternatives are required before selecting and installing the wind turbines to maximize their efficiency for hub heights within acceptable limits. Furthermore, energy output can be optimized by reducing the cut-in-speed and the rated speed by redesigning the blades; nevertheless, this is beyond the present paper's scope.

Quantitative assessment of wind resources is essential to successfully establish a wind farm at a given location. 
Often, wind energy resources are relatively abundant and efficacious along coastlines. Interestingly, the wind map of KSA is identified by two areas: (i) the Arabian Gulf and, (ii) the Red Sea coastline. As per the (Renewable Resource Atlas, n.d.), the annual average wind speeds are mostly between 6.0 and $8.0 \mathrm{~m} / \mathrm{s}$, across the country. However, these statistics do not include a wind power potential analysis that reflects the wind speed distributions over time. The efficient utilization of wind energy is highly governed by the type of turbines used. Although, the selection of a specific type of wind turbine is perplexing owing to several involved principles. The essential criteria include energy output, cut-in/rated wind speed, power rating, rotor diameter, and tower height, among others. Therefore, it is desideratum to develop know-how about these effects to provide the optimal balance between the selection criteria and variety of associated processes (Demirbas et al., 2017). In this study, the offshore wind turbine is chosen based on recommendations in the previous literature (Marih et al., 2020).

Moving offshore can accommodate larger structures which would provide robust power output. When installed offshore, wind turbines are expected to achieve a capacity of 3.5 MW. Offshore winds tend to blow faster and more consistently than onshore winds, which leads to higher electricity generation potential. The wind turbines also provide a more stable operation than wind systems based on land. It is notable that a small increase in wind speed yields higher energy production. The velocity of the available wind potential to harvest has a significant impact on the power production of turbines. Accordingly, careful site selection and larger turbine sizes are two vital parameters to amplify electricity efficiency through wind turbines.

Rehman et al. proposed a two-level decision turbine selection strategy based on fuzzy logic and a multi-criteria decision-making approach. They revealed that the proposed method is suitable for selecting optimal turbines within set of machines having different capacities (Rehman \& Al-Abbadi, 2009). Baseer et al. presented the wind characteristics and resource assessment in Jubail industrial city using measured hourly mean wind speed data at different heights (Baseer et al., 2017). Shaahid et al. investigated the economic feasibility of a $15 \mathrm{MW}$ wind power farm developed at Taif after analyzing the long-term wind speed data (Shaahid et al., 2019). Eltamaly et al. proposed a computer program to optimize the size of wind energy system for the sake of pairing between sites and wind turbines(Eltamaly et al., 2014). Furthermore, Eltamaly introduced a procedure to identify the most appropriate location and suitable wind turbines for different locations depending on the cost-effectiveness (i.e., minimum price of $\mathrm{kWh}$ generated) of the wind energy system (Eltamaly, 2013). Al-Ammar et al. studied the feasibility of design and construction of wind farms across KSA from geographic, economic, and technical perspectives. Rehman et al. studied wind characteristics and wind energy yield by measuring wind speed values at 20,30 , and 40 meters above ground level (Rehman, 2005; Rehman \& Al-Abbadi, 2009). Harireche et al. investigated Caisson installation for offshore structures (Farooq et al., 2019; Mehravar et al., 2016, 2017). To the authors' knowledge, very little research has been conducted regarding the loading, designing, and analyzing of onshore and offshore wind turbine structures in KSA. Salah et al. (Salah et al., 2019) assessed and analyzed the wind energy characteristics at different potential sites in KSA by estimating power generation levels and determining their suitable locations. Allhibi et al. (Allhibi et al., 2019) analyzed wind data of KSA for the last decade, and they recommended potential locations and wind turbine specifications across the country. The present paper deals with a feasibility study for installing wind farms considering the coastal conditions. Load analysis and is carried out for the feasible site, and then it proposes an optimized wind turbine alongside its hub height based on the analysis and design of the overlying superstructure (Al-Douri et al., 2019).

\section{Methodology}

This section is devoted to the methodology carried out in the present paper. A section showing the available energy is provided. This is followed by a load assessment for the wind turbine superstructure. These loads are combined as per recommended codes to further assess the structure of the wind turbine.

\subsection{Energy assessment}

According to the Renewable Energy Atlas, KSA is ranked $13^{\text {th }}$ globally with one of the highest onshore wind output capacity, that is naturally equipped with renewable energy sources. In KSA, higher wind speeds exist in the northeast, the central, and near the western mountainous regions. KSA has sufficient wind energy potential, with an average wind speed of $7.5-8 \mathrm{~m} / \mathrm{s}$ in the east coast regions, whereas 7-7.5 m/s on the western coast along the Red Sea. As a result, the wind data has been generated using the RETscreen software (Natural Resources Canada, 2013), as depicted from Figure 1. A comprehensive contour map of averaged wind speed at $10 \mathrm{~m}$ height from the ground, spanning 36 years (1983-2020), has been set up for KSA, as shown in Figure 2. The ongoing $400 \mathrm{MW}$ wind farm, located in Dumat Al Jandal, $896 \mathrm{~km}$ north of Riyadh, is considered as the largest wind power project of the region. This wind farm would supply electricity to Saudi Power Procurement Company in lieu of a 20-year power purchase agreement. This first step to accomplish the development plan of wind energy, in the context of the Kingdom's 2030 vision, is the anticipation for future consideration of offshore wind farms and their effective utilization (Guenoukpati et al., 2020).

The strategic planning for the diversification of electrical energy sources in KSA includes an ambitious plan (costing approximately 108.9 B USD) to integrate an installed capacity (up to $54 \mathrm{GW}$ ) with the help of renewable resources (Salah et al., 2019). This plan was initiated by King Abdullah City for Atomic and Renewable Energy (K. A. CARE) in 2012, wherein $9 \mathrm{GW}$ were initially allocated to wind energy only. This plan was intended to fulfill the ever-increasing energy demand caused by rising population growth, per capita consumption increase, and massive developing projects. The energy demand was forecasted to grow from 3.4 MBOE (Million Barrel of Oil Equivalent) in 2010 to $8.3 \mathrm{MBOE}$ in 2028. The plans have been perpetually revised and updated to date, as presented in Figure 2. 


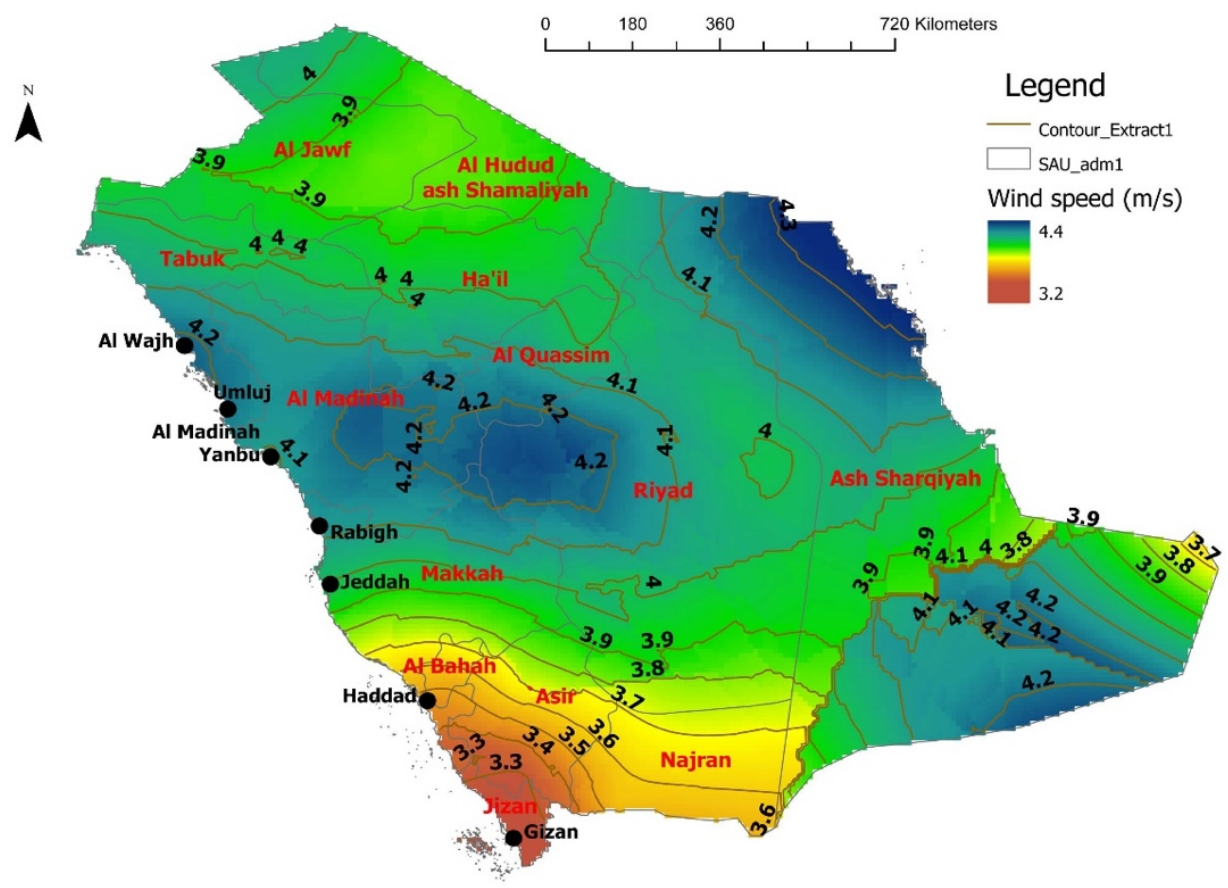

Fig. 1 Mean annual wind speed at $10 \mathrm{~m}$ height above ground level for KSA (RETscreen data 1983-2020)

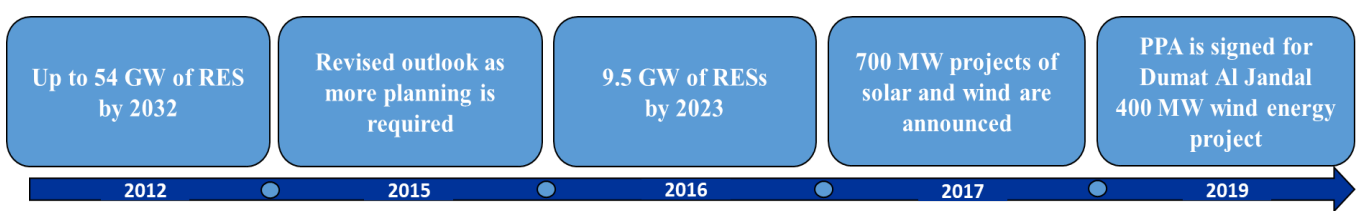

Fig. 2 Renewable energy projects plans across K.S.A

Table 1

Latitude, Longitude, and average wind speed at $10 \mathrm{~m}$ height above ground

\begin{tabular}{cccccc}
\hline S.No & City & Latitude & Longitude & $\begin{array}{c}* \text { Avg } \\
(\mathrm{m} / \mathrm{sec})\end{array}$ & $\begin{array}{c}\text { wind speed } \\
\text { GWA wind speed } \\
(\mathrm{m} / \mathrm{sec})\end{array}$ \\
\hline Site 1 & Al Wajh & 26.2 & 36.5 & 4.5 & 4.3 \\
Site 2 & Umluj & 25 & 37.3 & 4.3 & 4.0 \\
Site 3 & Yanbu & 24.1 & 38.1 & 3.7 & 3.7 \\
Site 4 & Rabigh & 22.8 & 39 & 4.3 & 3.6 \\
Site 5 & Jeddah & 21.7 & 39.2 & 4.1 & 3.9 \\
Site 6 & Haddad & 19.5 & 41 & 3.2 & 2.9 \\
Site 7 & Gizan & 16.9 & 42.6 & 3.1 & 2.8 \\
\hline
\end{tabular}

*RETscreen, ${ }^{* *} \mathrm{GWA}=$ Global Wind Atlas

The Red Sea coast in KSA stretches to about 2,000 km. Previous studies have shown that the northwestern coastal lines are more feasible for developing offshore wind farms from the standpoint of the economy. The offshore wind turbines are generally advantageous where wind is more reliable, that is also endorsed by the International Renewable Energy Agency (IRENA) ("Statistics Time Series," n.d.). The total onshore installed capacity in 2018 approached 539,557 MW in contrast to 23,629 MW installed offshore, leading to an annual generation of
$1,194,718 \mathrm{GWh}$ and $68,196 \mathrm{GWh}$, respectively. It reflects a higher average capacity factor for offshore wind energy with an average of $32.9 \%$ compared to $25.3 \%$ for onshore wind energy. Therefore, keeping in view these considerations, the current study aims to design an optimum turbine superstructure to be installed at $\mathrm{Al}$ Wajh region. In addition, the seabed profile and loading conditions related to wind, waves, and currents for the selected region are evaluated in detail and have been employed in the design afterward. 


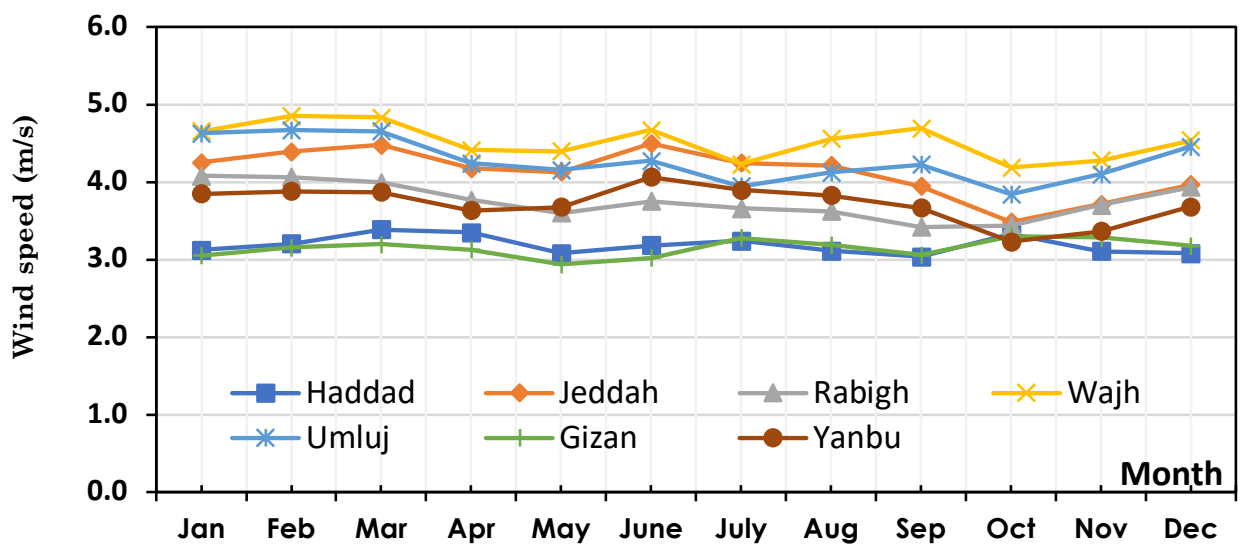

Fig. 3 Mean wind speed at $10 \mathrm{~m}$ height for selected locations for 36 years (1984-2019)

In this section, the average wind speed for three periods, such as 1984-1995, 1996-2007, and 2008-2019 are presented. The pertaining data has been obtained by using RETscreen software. Since the difference between the values of the wind speed obtained for these particular periods is minimal, the mean wind speed at $10 \mathrm{~m}$ height for 36 years (1984-2019) at the selected locations is given in Table 1 and illustrated in Figure 3.

The wind speed for different heights at Al-Wajh is computed according to the power-law expression (Eq. 1.)

$$
\frac{v}{v_{R}}=\left(\frac{H}{H_{R}}\right)^{\beta}
$$

where $B$ represents the friction coefficient (which is associated with the roughness of the terrain). It can be computed by using Eq. 2, and its value ranges typically between 0.05 and 0.5 (Luo \& Hong, 2013). Hence, the impact of offshore wind harvesting with a lower friction coefficient is evident, which then leads to higher power production.

$$
\beta=\frac{0.37-0.088 \operatorname{In}\left(v_{R}\right)}{1-0.088 \operatorname{In}\left(\frac{H_{R}}{10}\right)}
$$

Usually, it is imperative to measure Wind Power Density $\mathrm{P}_{\mathrm{D}}$ to observe the available wind energy at any location. It must be noted that the calculation of WPD includes the effect of wind velocity and air density. Figure 4 shows the wind power density for sites considered in this study. It can be observed that the amount of wind energy at $\mathrm{Al}$ Wajh outperforms all other regions. Wind power $\mathrm{P}$ and Wind power density $P_{D}$ are given by Eq. 3 and Eq. 4, respectively. Besides, Eq. (5) links the power generation to the height.

$$
P=\frac{1}{2}\left[\rho C_{p} A v^{3}\right]
$$

$$
\begin{aligned}
& P_{D}=\frac{1}{2}\left[\rho C_{p} v^{3}\right] \\
& \frac{P}{P_{R}}=\left(\frac{\frac{1}{2}\left[\rho C_{p} A v^{3}\right]}{\frac{1}{2}\left[\rho C_{p} A v_{r}^{3}\right]}\right)=\left(\frac{v}{v_{r}}\right)^{3}=\left(\frac{H}{H_{R}}\right)^{3 \beta}
\end{aligned}
$$

The rotor efficiency refers to the ability of turbine to extract electrical energy from the available potential energy in the wind. The maximum rotor efficiency that a wind turbine can reach is computed by determining the Betz limit. Suppose that the wind's velocity through the rotor plane is the average of the speeds, while the upwind and downwind are considered; the power is calculated by Eq. 6.

$$
\begin{aligned}
P_{b} & =\frac{1}{2} \rho A\left(\frac{v+v_{d}}{2}\right)\left(v^{2}-v_{d}^{2}\right) \\
& =\frac{1}{2} \rho A v^{3}\left[\frac{1}{2}(1+\lambda)\left(1-\lambda^{2}\right)\right]
\end{aligned}
$$

The calculated maximum rotor efficiency equals 0.593 , i.e., it is the maximum efficiency that a wind turbine rotor can achieve. It can be attained by slowing the upwind speed by about one-third. Moreover, the ratio of average power produced to the required power is known as the "capacity factor,' denoted by $\mathrm{C}_{\mathrm{f}}$ (Eq. 7).

$$
C_{f}=\frac{P_{\text {produced }}}{P_{\text {required }}}
$$

$\mathrm{C}_{\mathrm{f}}$ of the wind turbines increases due to larger turbines, higher swept areas, and greater hub heights. A wide range of $\mathrm{C}_{\mathrm{f}}$ is reported in the available literature due to the meteorological differences at various locations, the impact of technologies adopted, and the type of farm configurations. In 2019, the average $\mathrm{C}_{\mathrm{f}}$ of offshore wind projects ranged from $30 \%$ in Japan to $52 \%$ in the United Kingdom ("Renewable Power Generation Costs in 2019," n.d.). 


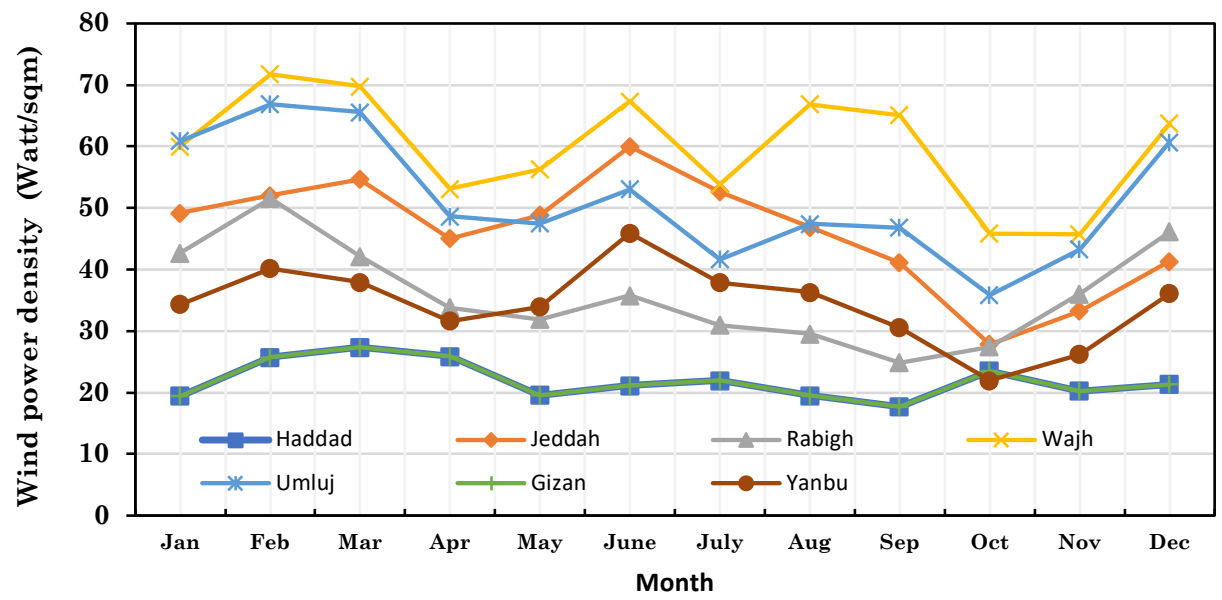

Fig. 4 Wind Power Density (WPD) for the sites considered in this study
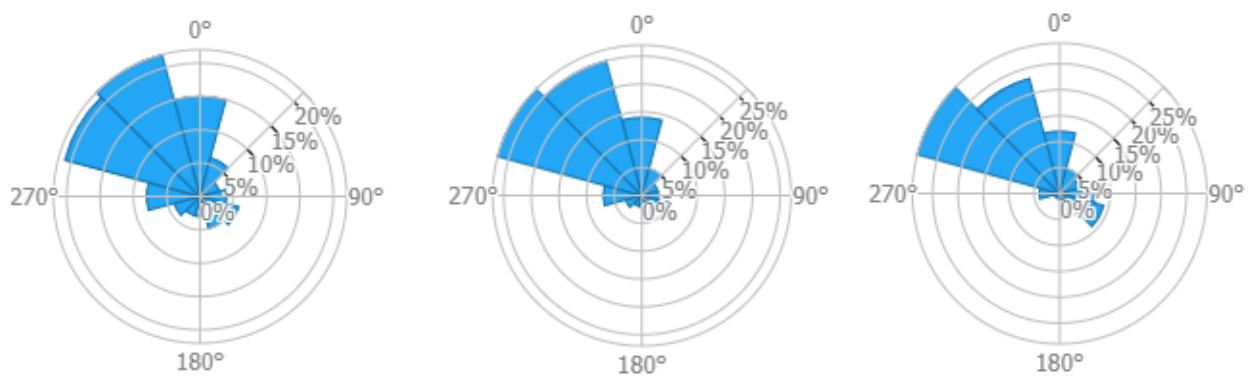

Fig. 5 Wind roses (left) wind frequency, (center) wind speed, and (right) wind power (\%)

Several studies have been devoted to study the wind direction and its effect along the hub height. A study (Sanchez Gomez \& Lundquist, 2020) shows that changes in wind direction with height should be considered when analyzing turbine performance. For this purpose, wind roses are analyzed in the present study, and it was found that the dominant wind direction is shown in Figure 5. For Al-Wajh region, wind roses are the facing velocity bins, whereas direction sections are also illustrated. This depicts that the wind strength in the prevailing direction is NW. From the chart area, the distribution of wind strength over the entire year is shown where the start of the windy season can be observed.

Since the national oil consumption in KSA is increasing by $7 \%$ annually, the domestic demands are expected to be doubled in the coming decade, which is alarming for the environment (Al-Douri et al., 2019). Renewable energy, such as wind technology, can help improve environmental conditions by reducing Greenhouse Gases (GHG) emissions. Assessments are required to characterized and evaluated the life cycle greenhouse gas (GHG) emissions from different wind electricity generation systems such as wind turbines (Kadiyala et al., 2017). In this regard, the annual GHG emission reduction indicates the corresponding decrease in $\mathrm{CO}_{2}$ emission due to the use of wind turbines. Additionally, the gross GHG emission reduction represents the total amount of $\mathrm{CO}_{2}$ emission reduction in the whole life cycle. It is to say that wind turbine technology has immense fuel-saving potential. For instance, in the present case, the gross annual GHG emission reduction is about $93 \%$. A comparison between a "base case", typically the conventional techniques such as generation of energy from crude oil etc., and a "proposed case", i.e., the wind energy, obtained from the emission analysis conducted using RETscreen model (Natural Resources Canada, 2013), and it is provided in Figure 6.

A suitable location necessitates better wind turbine performance. For this purpose, it is required to have an optimal design for achieving a reliable response in diverse weather conditions. Service conditions may correspond merely to a breeze on a low-lying plain or a raging offshore storm, and a lowland site might have an average wind speed of $6 \mathrm{~m} / \mathrm{s}$. In contrast, an exposed site on the top of a hill might have an average wind speed of $9 \mathrm{~m} / \mathrm{s}$. In this regard, Class II turbines are commonly recommended for sites which witness up to $8.5 \mathrm{~m} / \mathrm{s}$ average wind speed. Generally, majority of the OWT support structure designs are based on IEC's recommendations 61400-3 (IEC, 2005; International Eletrotechnical Commision, 2005). However, there are also other design guidelines, such as DNV (Veritas, 2010) and GL (Germanischer Lloyd, 2013).

\subsection{Load assessment}

Subsea conditions (i.e., current, wave kinematics, wavecurrent interactions), sea surface conditions (i.e., wave spectra, directionality/spreading, wind), water depth, and tidal range must be evaluated prior to installation of any wind farm. It is noteworthy to mention that the offshore site conditions have a significant influence on the design. 
Citation: Naqash, M.T., Aburamadan, M.H., Harireche, O., AlKassem, A., Farooq, Q.U. (2021). The Potential of Wind Energy and Design Implications on Wind Farms in Saudi Arabia. Int. Journal of Renewable Energy Development, 10(4), 839-856, doi: 10.14710/ijred.2021.38226

$\mathrm{P}$ a g e $\mid 844$

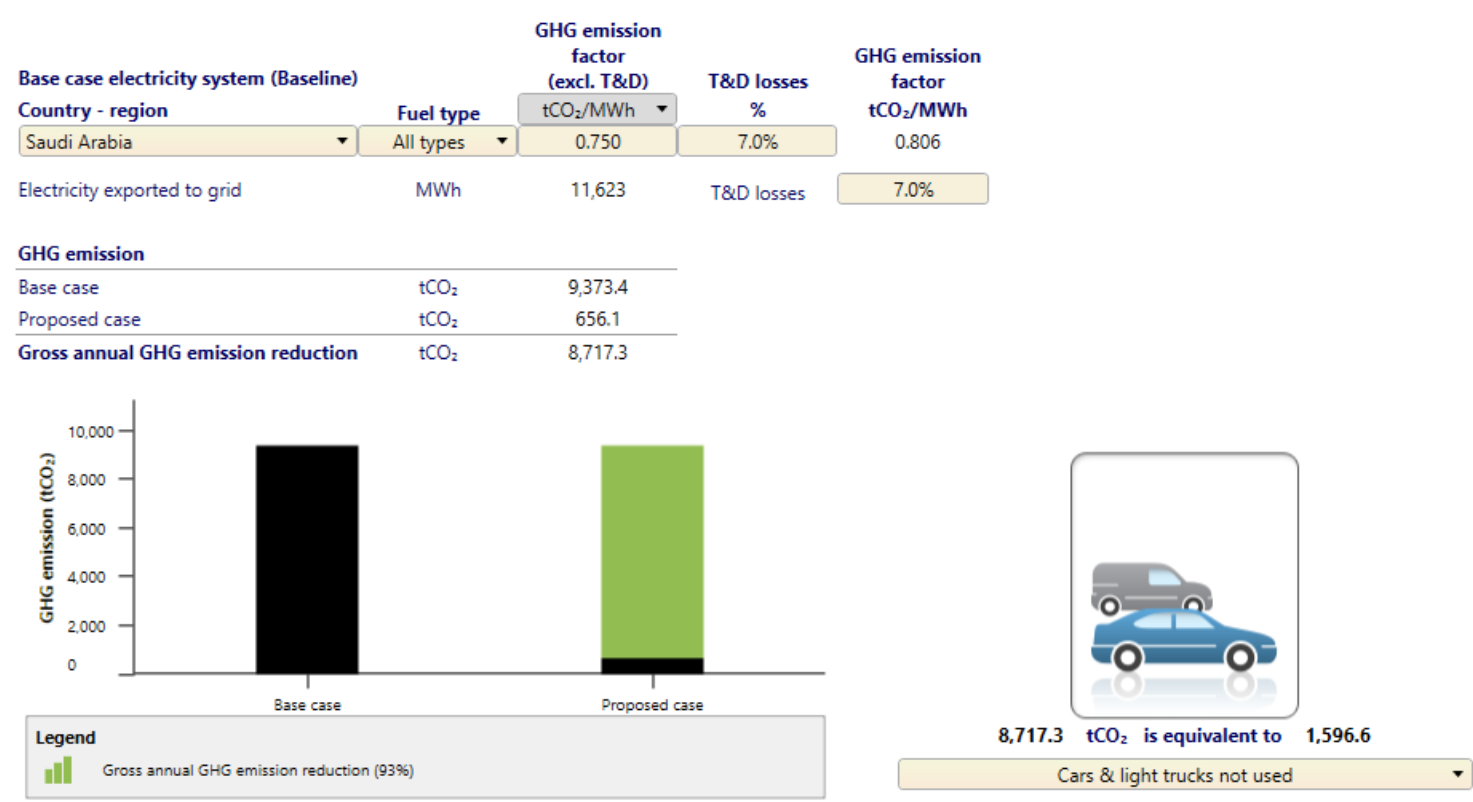

Fig. 6 GHG equivalence (93\% Gross annual GHG emission reduction)

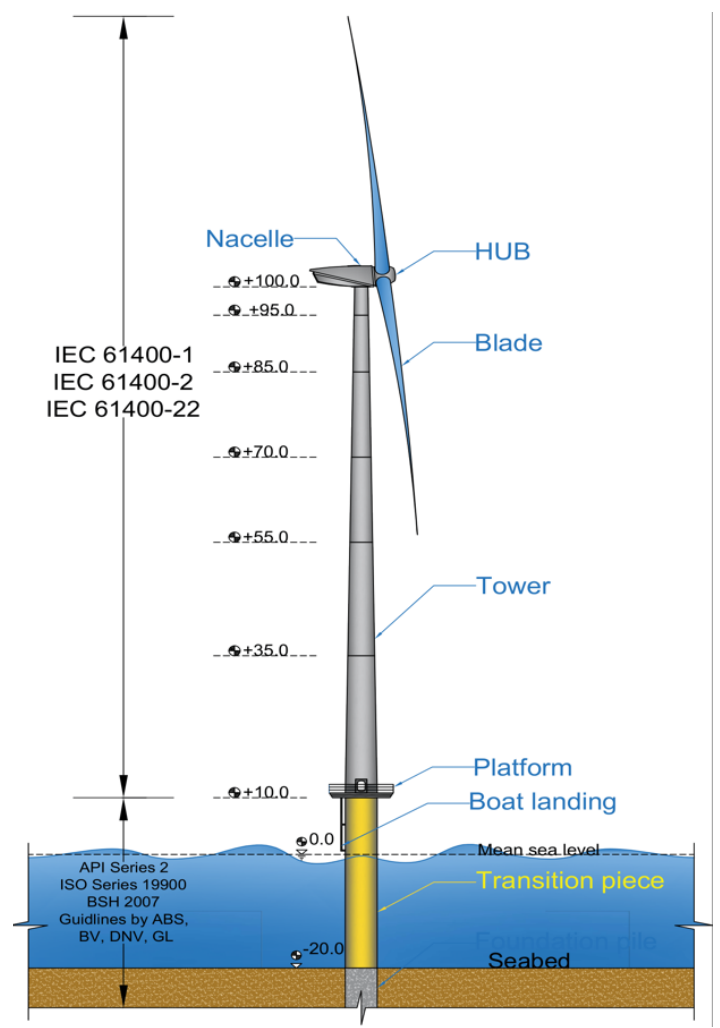

Fig. 7 Components and Standards for the assessment of offshore wind turbine structure

A modal analysis is conducted using SAP2000 to assess the monopile models and to evaluate the OWT's response supported fixed foundation. The loadings on the OWT model are considered in order to evaluate the strength and performance of the monopiles under different load cases, as suggested by API RP 2A-WSD
(Recommended Practice for Planning, Designing and Constructing Fixed Offshore Platforms - Working Stress Design API Recommended Practice 2A-WSD (RP 2AWSD), 2000) and NORSOK N-004 (NORSOK: N-003 Actions and Action Effects, 2007) standards. Variety of 
codes that can be incorporated for various components of the OWT are shown in Figure 7.

Wind Class III has been selected because the average annual wind speed at Al-Wajh is around $7.5 \mathrm{~m} / \mathrm{sec}$. Siemens SWT-3.6-107 Offshore turbine manufactured and commissioned by Siemens Germany are chosen in the current work. This turbine weighs $225 \mathrm{t}$ (weight of Nacelle: 125 tons, Rotor + Hub: 100 tons). It exhibits a rated power of $3,600 \mathrm{~kW}$, a rotor diameter of $107 \mathrm{~m}$, a swept area of $8,992 \mathrm{~m}^{2}$, and a specific area of $2.5 \mathrm{~m}^{2} / \mathrm{kW}$. In addition, the selection of Siemens SWT-3.6-107 turbine is done based on its widespread applications in several wind farms. For instance, the offshore wind farm located in Dan Tysk, Germany, comprises 80 such units with a capacity of 3.6 MW (costing approximately $1000 \mathrm{M} €$ ) (Saigal et al., 2007). The Max water depth at the site is approximately $31 \mathrm{~m}$, at a distance of about $70 \mathrm{~km}$ from the shore. The hub height is $95 \mathrm{~m}$, with a rotor diameter of $120 \mathrm{~m}$. The total site area is $66 \mathrm{~km}^{2}$. The projected $\mathrm{C}_{\mathrm{f}}$ for the turbines is $51.5 \%$ with a planned annual net output of $1,300 \mathrm{GW} \cdot \mathrm{h}$ (Siemens Gamesa, n.d.).

The steel towers of wind turbine must be economical and safe in terms of design. However, a tower that exceeds a $100 \mathrm{~m}$ height can be uneconomical due to requirement of additional materials for upkeeping strength while ensuring safe design. In this paper, the selection of dimensions and thicknesses of the steel tower are largely governed by the deflection limitation and strength parameter. Using the design flowchart shown in Figure 14, several iterations are done and the steel tower dimensions are as: height from the mean sea level $=100 \mathrm{~m}$, top dia $=2.1 \mathrm{~m}$, bottom dia $=5 \mathrm{~m}$ with a uniform thickness of $40 \mathrm{~mm}$ and transition a piece of $30 \mathrm{~m}$ height and dia $5 \mathrm{~m}$ are considered.

Structural steel (S450) with a minimum yield stress of $450 \mathrm{~N} / \mathrm{mm}^{2}$ is adopted to satisfy different acceptance criteria. The $100 \mathrm{~m}$ tall conical tower of the wind turbine consists of three blades, each measuring $52 \mathrm{~m}$ in length, connected with a rigid hub, and attached to a nacelle that contains the mechanical and electrical components of the turbine. The superstructure supporting an OWT is a vertical cantilever support for the blades. In order to perform analysis, the adopted structural model is based on shell elements, whereas, Euler-Bernoulli beam element is considered to estimate the loading for the shell elements. The masses of nacelle and hub are considered to be lumped at the top of the tower. Finally, the wind turbine tower is designed as a tubular steel tower pinned at the base with the foundation using anchor bolts.

The installation of wind turbines beyond a certain depth is not feasible which leads to an increased cost. Hence, bathymetry decides the type and cost of the preliminary structure. The conceivable depth for turbine installation is $15 \mathrm{~m}$ to $40 \mathrm{~m}$, beyond which installation is cumbersome and conservative. Both the seabed condition and the bathymetry allow for the choice of foundation. In this study, shallow water is considered, such that the depth is $20 \mathrm{~m}$ to $30 \mathrm{~m}$ at Al-Wajh. Therefore, monopile is usually driven into the seabed and a transition piece is attached that provides an extension of the tower. This is deemed as the most appropriate type of foundation for the aforementioned water depth. It is worthy to state that AlWajh encompasses approximately $2,880 \mathrm{~km}^{2}$ area, extending $26 \mathrm{~km}$ to $50 \mathrm{~km}$ offshore from the mainland, and having a shoreline of about $50 \mathrm{~km}$. Moreover, the central lagoon traverses an area of about $1,400 \mathrm{~km}^{2}$, with a maximum depth of $30 \mathrm{~m}$ to $40 \mathrm{~m}$ whereas it becomes shallower toward land (Bruckner et al., 2011).

As per ASCE/AWEA 2011 (AWEA, 2011), the general requirements for the development of wind farms includes site feasibility, turbine selection, and specific design conditions at the site. Also, the IEC 61400 (International Electrotechnical Commission) specifications (IEC, 2005; International Eletrotechnical Commision, 2005) provide guidance on wind turbine design, manufacturing, transportation, and installation. Local building codes such as Saudi Building Code (SBC) (SBC, 2020) must be satisfied during the preliminary design basis for OWT support structures. As per Saudi Aramco database (Ref. No SAES A-112), the basic 3 -second gust, $\mathrm{km} / \mathrm{h}, 50$ yrs return period $=145 \mathrm{Km} / \mathrm{h}(40.3 \mathrm{~m} / \mathrm{s})$ at $10 \mathrm{~m}$ above the ground level, which is reference elevation for SAES-A-112with exposure category C. The prevailing direction is West-North West (WNW), as per the SBC. A wind shear exponent a of 0.2 is converted from $10 \mathrm{~m}$ to $100 \mathrm{~m}$ in accordance with the IEC 61400-1 specifications. From Eq 8, it can be observed that Vhub equals $63.9 \mathrm{~m} / \mathrm{s}$ at $100 \mathrm{~m}$. Additionally, the normal wind profile showing the wind speed along the height is shown in Figure 8.

$$
V(z)=V(h u b)\left(\frac{z}{z_{h u b}}\right)^{\alpha}
$$
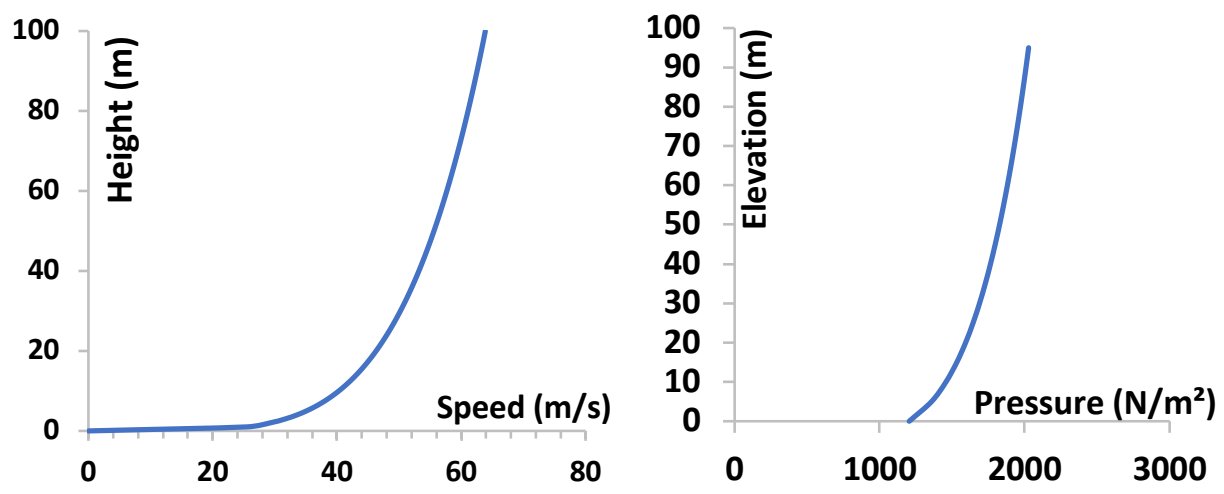

Fig. 8 Normal wind profile model (left) and wind pressure values at height z (right) 
The 'current load' is defined as velocity and the direction of current as a function of depth, from the stormwater level to the mudline level. A set of inputs are required to define the current profile, such as the current blockage factor (bf) and velocity and direction at specific elevation/s from the datum. The $b_{f}$ of offshore platforms with less than 3 legs can be calculated using Eq. (9), as per API recommended practice (API 2A-WSD, 2014).

$$
\begin{gathered}
\text { blockage factor }=\left[1+\sum \frac{\left(C_{d} A\right)_{i}}{4 A}\right]^{-1} \\
R_{e}=\frac{U_{m} D}{v}=4.33 \times 10^{6}
\end{gathered}
$$

Considering $\mathrm{b}_{\mathrm{f}} \approx 1.0$, which ranges from 0.7 to 1.0 as per API recommended practice while the corresponding the $\mathrm{C}_{\mathrm{d}}$ $\approx 0.65$. The current effect is minimal and can be neglected in general cases. Thus, the structure tends to produce waves due to which diffraction forces are generated. However, these values are almost negligible in contrast to the realistic values of current which act on a real-sized member. Besides, the current speeds are exhibit high levels of uncertainty. In this regard, a conservative modeling approach is to assume a constant current velocity along with the depth. The velocity value may be assumed as the maximum value expected in 50 years. It may be taken as $1 \%$ of the 50-year extreme mean wind speed. Another modeling approach is to increase the wave height by 10 to $15 \%$ while neglecting the current. In this study, the current value is assumed to be $1 \%$ of the 50 -year extreme mean wind speed $(52.5 \mathrm{~m} / \mathrm{s})$, i.e., around $0.53 \mathrm{~m} / \mathrm{s}$. Besides, the model is subjected to three different types of load scenarios, each with different wave heights. Thus, three current values of $0.4,0.5$ and 0.6 are selected for load scenarios 5 , 6 , and 7 , respectively.

A basic wind speed of $145 \mathrm{kph}, 3$-sec gust, and 50 years return period is selected for the OWT tower design, as per Aramco Metrological and Seismic Design Data (SAES-A-112). ASCE 7-16 ("Minimum Design Loads and Associated Criteria for Buildings and Other Structures," 2017) suggests that the, exposure category D should be applied with a surface roughness D which accounts for flat, unobstructed area, and water surfaces. As per ASCE 7-16, a topographic factor, $\mathrm{K}_{\mathrm{zt}}=1.0$, and wind directionality factor, $K_{d}=1$, is considered for round symmetrical structures. The flexible gust factor, $\mathrm{G}_{\mathrm{f}}=0.95$, is calculated for sensitive or dynamic structures, considering flexible structure. The fundamental natural frequency is less than $1 \mathrm{~Hz}$ and the solid/gross area ratio is 0.5 for frame elements (turbine blades). Moreover, half of the total surface area is subjected to the wind load in the wind direction. According to the considered load combinations, both wind load and turbine load should be applied separately with by using different load factors. To achieve this, the steel tower is modeled as a shell structure in the current study. The wind turbine blades are modeled as frame elements because SAP2000 applies an open structure wind load that targets any frame elements in the workspace. A wind load is applied on shell elements with a pressure coefficient $C_{p}$ equalling 0.8 . The typical values of wind pressure coefficients for cylindrical members range from 0.7 to 1.2 . An open structure TWL is applied to the steel blades (frames) with a wind direction angle equals to $90^{\circ}$. For the distributed load on the tower, the velocity pressure is calculated according to Eq. 11.

$$
q_{z}=0.613 K_{z} K_{z t} K_{d} K_{e} V^{2}
$$

To calculate the velocity pressure at elevation $\mathrm{z}$, the velocity exposure coefficient $\mathrm{K}_{\mathrm{zt}}$ should be determined at each elevation z, using Eq. 12:

$$
K_{z t}=2.01\left(\frac{z}{z_{g}}\right)^{\frac{2}{\alpha}}
$$

The pressure values multiplied by half of mean diameter of the steel tower, in order to obtain distributed load per meter. The distributed load values help to calculate deflection values under wind load, as mentioned in the forthcoming section. However, an equivalent distributed load can be calculated by taking the average of non-uniform load values, which yields an average distributed 6.23 $\mathrm{kN} / \mathrm{m}$. All loads that are considered in this study on the OWT are shown in Figure 9.

Furthermore, the mechanism of current resembles that of wind, while their velocities vary in time and space. However, the length and timescales of the variations are more pronounced in the case of currents. This prompts the consideration that currents witness horizontal uniform flow field of constant velocity, i.e., a function of only the vertical coordinate. Bai and Jin (You et al., 2018) studied currents into tidal, loop-eddy, circulation, and storm-generated. It is notable that the total effect of these currents is in the form of a vector sum. The variation of current speed and direction with elevation is represented by a current whose total profile is associated with an extreme storm sea and should be specified.

Wind, temperature, gravity, and Earth's spin about its axis are the primary sources generating currents on the surface of the oceans. Near-surface currents have a profile following a power law, and their magnitude changes exponentially with depth. Moreover, the magnitude of subsurface currents varies linearly down to a certain depth, then remain constant. Nearshore currents, however, have a fixed current profile, independent of the depth. SAP2000 auto-generated criteria of the wave and the current definition are adopted here. The contour diagram in Figure 10 shows the magnitude of the resultant horizontal wave velocity for a wave of $4 \mathrm{~m}$ height across $4 \mathrm{sec}$ period. The legend displayed at the bottom shows maximum and minimum values for the horizontal wave velocity.

Sea waves result from the wind blowing across the water surface. They form one of the major components of environmental forces thereby affecting the OWTs. These often start as small ripples and can grow considerably with time. As the waves hit the OWT foundation, they cause considerable action whose magnitude depends on the wave height and wave period. Waves are random, varying in height and length; Furthermore, Bai and Jin state that the 
waves can approach an OWT from more than one direction simultaneously. Due to this random nature, the sea state is usually described in statistical wave parameters, such as; effective wavelength, spectral peak period, spectral shape, and directionality. Waves are the primary loads acting on the submerged part of the OWT.
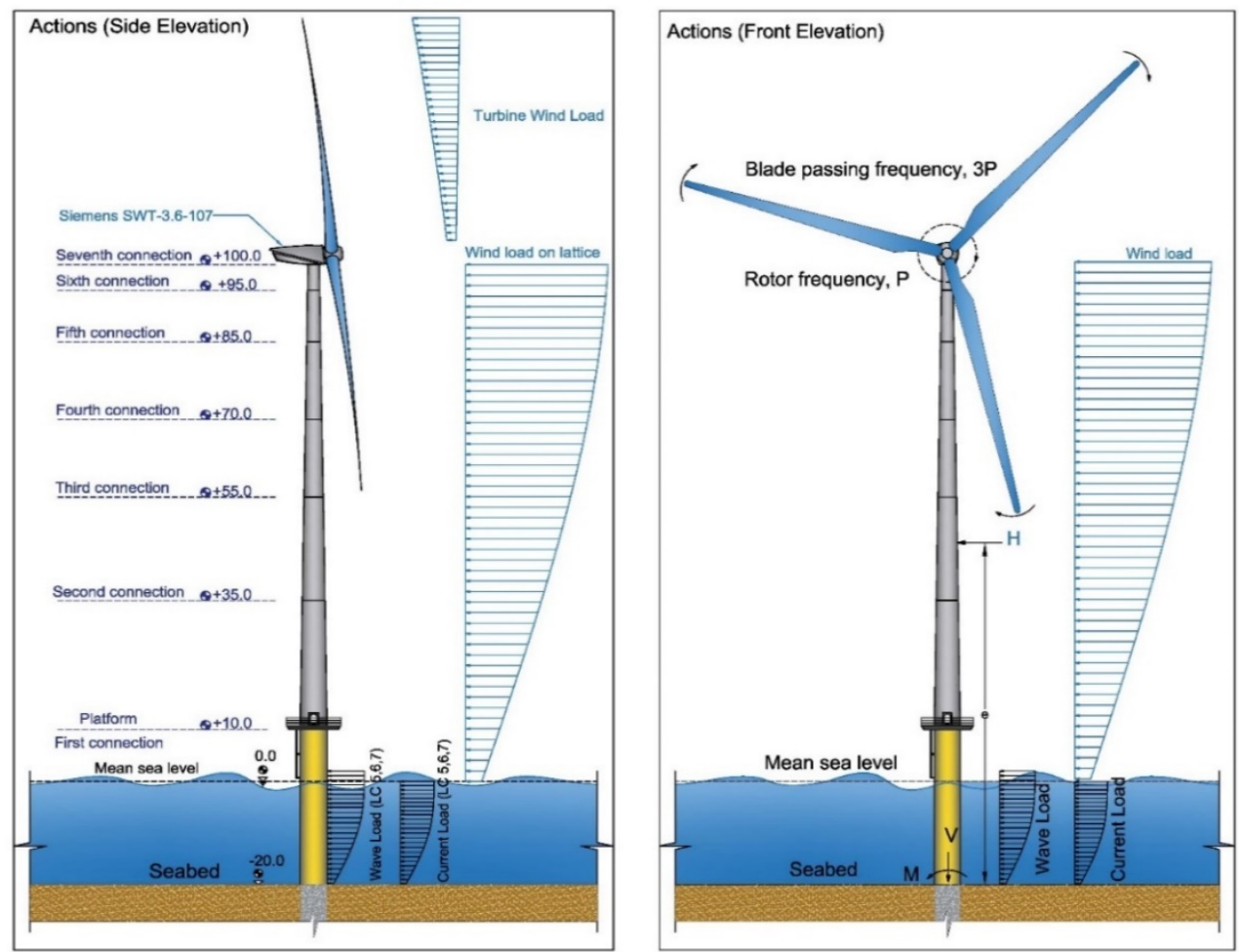

Fig. 9 Calculated Loads on the wind turbine (left) Side elevation, (right) front elevation.

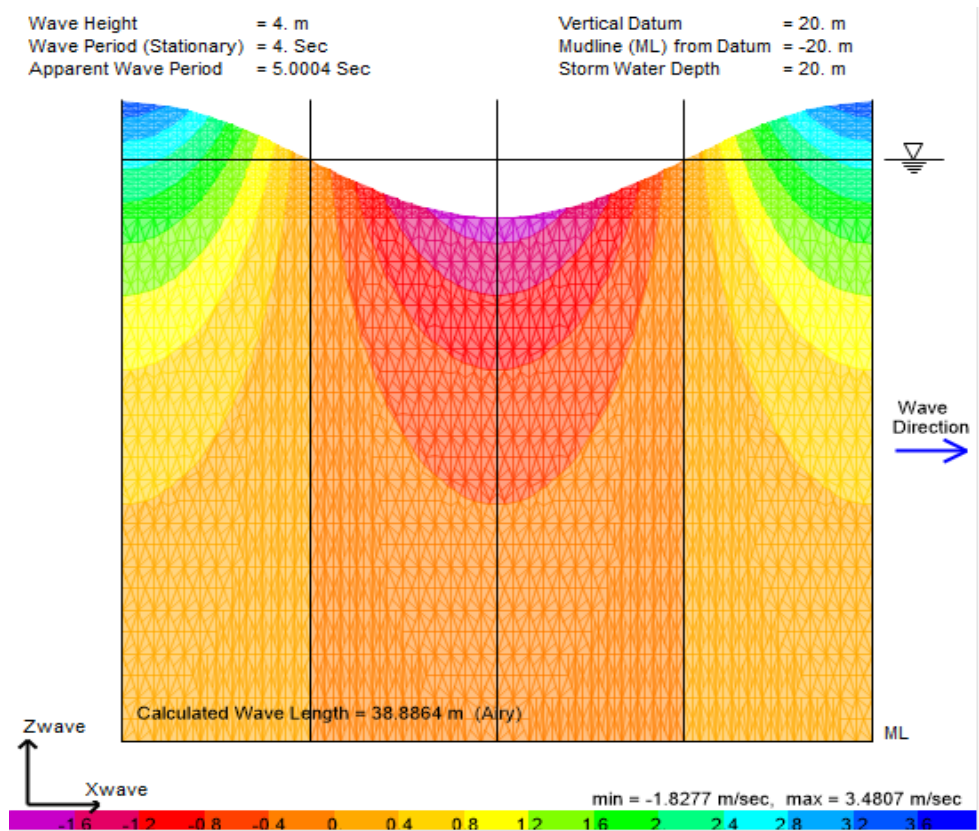

Fig. 10 Wave velocity contours for a wave height of $4 \mathrm{~m}$ and a wave period of $4 \mathrm{sec}$ 
Nevertheless, these are considered for the superstructure design in the present study. In the case of regular waves, properties are invariant from cycle to cycle and are dominated mainly by three parameters: Period $T$, height $H$, and water depth $d$. Moreover, over the past decade or two, several regular wave theories have been developed. The linear Airy wave theory has been applied in this study, which usually shows accurate and reliable predictions. The code generates the kinematic properties, velocity, and acceleration of particles in propagation in the vertical direction. This particular theory is accepted for slender members where wave loads can be assessed using Morison's formula.

Seismic loading in some regions has little or no earthquake risk. On the contrary, some parts are incredibly susceptible to substantial seismic activity, and earthquake loading may be one of the governing factors. Therefore, for OWT the primary design usually requires a specific seismic site-study. The effect of seismic activity on an OWT varies in magnitude and it is dependent on the type of substructure. In this study, seismicity is not considered, since it requires specific attention, therefore authors aimed to focus it in their future work. Lastly, the probability of accidental loads on OWT is low; nevertheless, it is worth mentioning that ship collisions must also be considered during the design phase.

\subsection{Load combinations}

The tower transfers the forces (wind, mass, and elastic) onto the Rotor and Hub which are subsequently distributed to the foundation. According to the time-related effect of these forces on the turning turbine rotor, the different loads from these forces are: Aerodynamic loads, Stationary but having uneven flow field, Mass forces resulting from the rotating blades, and Non-periodic and random loads caused due to wind turbulence. To design a robust structure, it is desideratum that the reliability of the system subjected to loads should be considered. Analyzing the structural integrity of the structure for different limit states must also be reflected in the design. Fatigue limit state (FLS), ultimate limit state (ULS), accidental limit state (ALS), and serviceability limit state (SLS) are the primary limit states defined for various scenarios countered while designing the marine structures. ASCE 7 recommends different loading combinations, as mentioned in Table 2. In addition to the ASCE combinations, further load combinations are considered to analyze the response of the tower. It must be noted that the earthquake load is not considered in this work.

For the wind turbine structure, different load patterns are assumed as per the available literature, therefore in this case stormwater depth is taken as $20 \mathrm{~m}$ in accordance with the bathymetric data of Al-Wajh city, while a wave height (max) of $4 \mathrm{~m}$ (Langodan et al., 2017; Ralston et al., 2013) is considered to ensure the highest loading condition, knowing that the occurrence of wave heights of more than $2 \mathrm{~m}$ is less than $2 \%$. The wave periods are set from 4 to 7 seconds, such that the data from 1985 to 2014 shows that the mean wave period did not exceed 7s. However, in this study, the steel tower is modeled with 4 to 7 seconds periods. Each period is in a separate load case to account for the maximum loading effect on the tower. This study's monopole is modeled as shell elements using SAP2000 code (Structural Software for Analysis and Design | SAP2000, n.d.), whereas the wave loads are assigned accordingly. Additionally, the distributed load values for load cases 5, 6, and 7 are shown in Figure 11.

An approximate equivalent surface pressure considering $5 \mathrm{~m}$ strip is obtained from the beam model. It is performed by taking the average of each 4 consecutive values from the distributed load. These values are based on the wave parameters in load cases 5, 6 and 7, and dividing it by half of the transition piece diameter. The resulting surface pressure values for load cases 5, 6, and 7 are shown in Figure 12.

A transition piece is generally adopted for the supporting structure. The lower support structure beneath the offshore wind tower connects the tower and monopole under the sea and must act efficiently. Foundations for OWTs can be classified into two main types: the fixed types and floating types. The fixed type foundations are practical in relatively shallow waters of depth less than 60 $\mathrm{m}$. In contrast, the floating-type foundations are developed for deeper waters with depths higher than $60 \mathrm{~m}$. Fixed foundations such as monopile and gravity-based foundations are efficacious in shallow waters whose depth is less than $30 \mathrm{~m}$. In the present case, the latter is considered for modeling purposes.

Table 2:

Considered load combinations based on ASCE and bathymetry at the selected location.

\begin{tabular}{cccccccc}
\hline Load Case & Dead (DL) & $\begin{array}{c}\text { Wind } \\
(\mathrm{WL})\end{array}$ & $\begin{array}{c}\text { Wave } \\
(\mathrm{TWL})\end{array}$ & $\begin{array}{c}\text { Current } \\
(\mathrm{CL})\end{array}$ & $\begin{array}{c}\text { Earthquake } \\
(\mathrm{EL})\end{array}$ & Remarks \\
\hline 1 & 1.4 & 0 & 0 & 0 & 0 & $\mathrm{NC}$ & ASCE \\
2 & 1.2 & 1.6 & 1.35 & 0 & 0 & $\mathrm{NC}$ & ASCE \\
3 & 0.9 & -1.35 & -1.6 & 0 & 0 & $\mathrm{NC}$ & ASCE \\
4 & 1 & 1 & 1 & 0 & 0 & $\mathrm{NC}$ & ASCE \\
5 & 1 & 0 & 0 & $\mathrm{H}=4, \mathrm{~T}=4$ & $0.6 \mathrm{~m} / \mathrm{sec}$ & $\mathrm{NC}$ & \\
6 & 1 & 1 & 1 & $\mathrm{H}=2, \mathrm{~T}=7$ & $0.5 \mathrm{~m} / \mathrm{sec}$ & $\mathrm{NC}$ & \\
7 & 1 & 1 & 0 & $\mathrm{H}=4, \mathrm{~T}=5$ & $0.4 \mathrm{~m} / \mathrm{sec}$ & $\mathrm{NC}$ & \\
\hline
\end{tabular}

NC: Not considered 

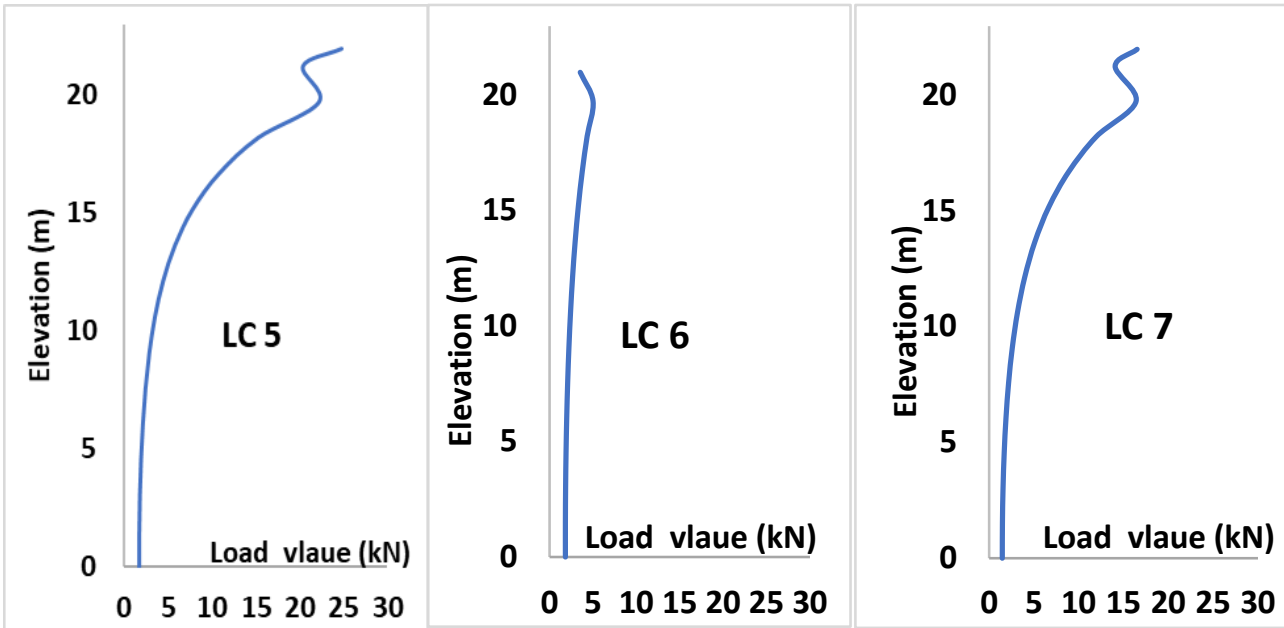

Fig. 11 Wave load in kN/m for LC5, LC6, and LC7

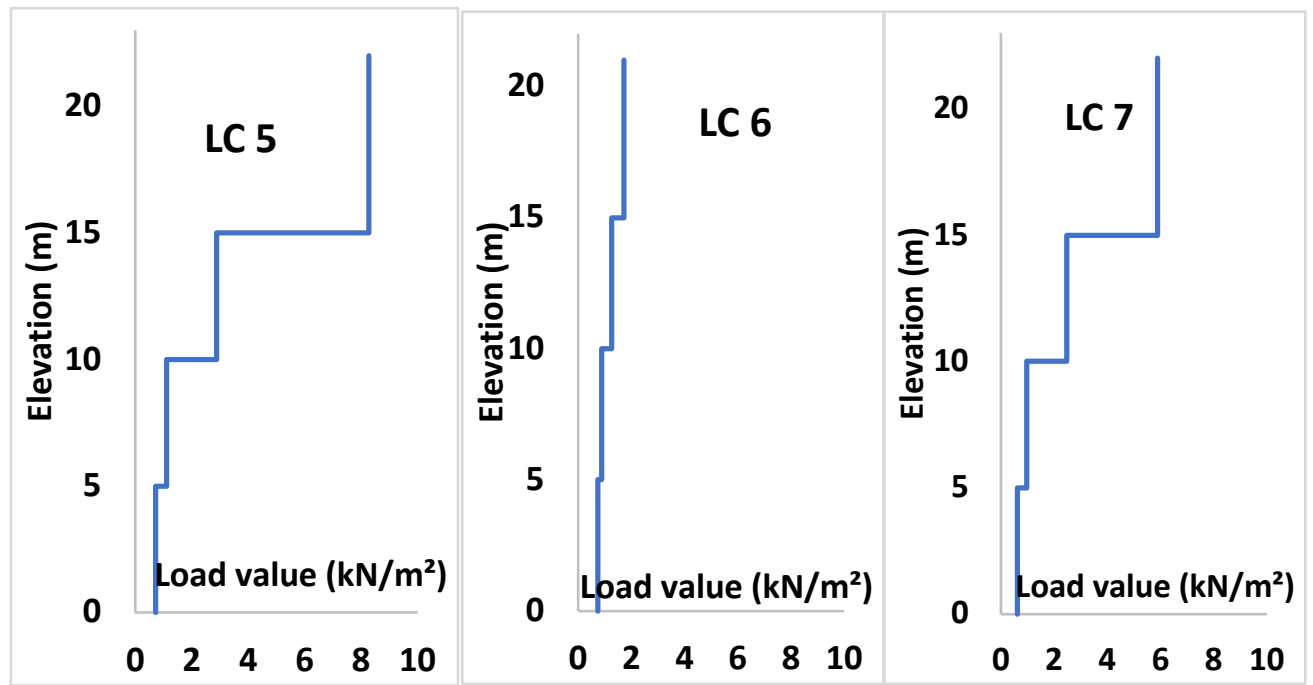

Fig. 12 Equivalent surface wave load in $\mathrm{kN} / \mathrm{m}^{2}$ for $\mathrm{LC} 5$, LC6, and $\mathrm{LC} 7$

\section{Modelling}

In this section the numerical model is presented in which the steel tower is modeled as a truncated hollow cone with a base diameter of $5 \mathrm{~m}$ and $2.1 \mathrm{~m}$ at the top. The hub height $(90 \mathrm{~m})$ and transition piece from the mudline (30 $\mathrm{m})$ gives an overall height from the mudline $(120 \mathrm{~m})$, with a drag coefficient of 1.2. The blades have a Young's Modulus of $700 \mathrm{Gpa}$ with drag coefficient of 2.0. The offset from the tower and the rotor plane is $4 \mathrm{~m}$. As shown, the tower is modeled with three blades; the dynamic effects of the rotating blades are not considered. The wind speed at 100 $\mathrm{m}$ height is calculated as $59 \mathrm{~m} / \mathrm{s}$ with a $2 \mathrm{~m} / \mathrm{s}$ standard deviation. To calculate the self-weight of both of the rotor and the blades, a rotor with the specified dimensions is defined: a) A rotor diameter of $3 \mathrm{~m}$ with a conical shape having $4.5 \mathrm{~m}$ length, and thickness equaling $16 \mathrm{~mm}$, b) A tapered blade section of a $3000 \mathrm{~mm}$ diameter at the hub and $500 \mathrm{~mm}$ at the end, with thickness of $14 \mathrm{~mm}$.

These sections are chosen to approximate the selfweight, as per Siemens SWT-3.6-107 geometric properties. The blades and rotor are considered to be connected to a linear link with fixed support for obtaining the dead load in the $\mathrm{R} 1$ direction, as shown in Figure 13. The whole model is analyzed for the dead load to obtain the total selfweight, thus ensuring the appropriateness of the values prior to defining and assigning the wind, wave, and current loads. The total reaction at the support of all parts of the wind turbine, including the nacelle's weight of 125 tons equals 493 tons in vertical direction with a moment in Y direction equals 412 tons-m. The flowchart for the design and analysis of the tower is shown in Figure 14. 


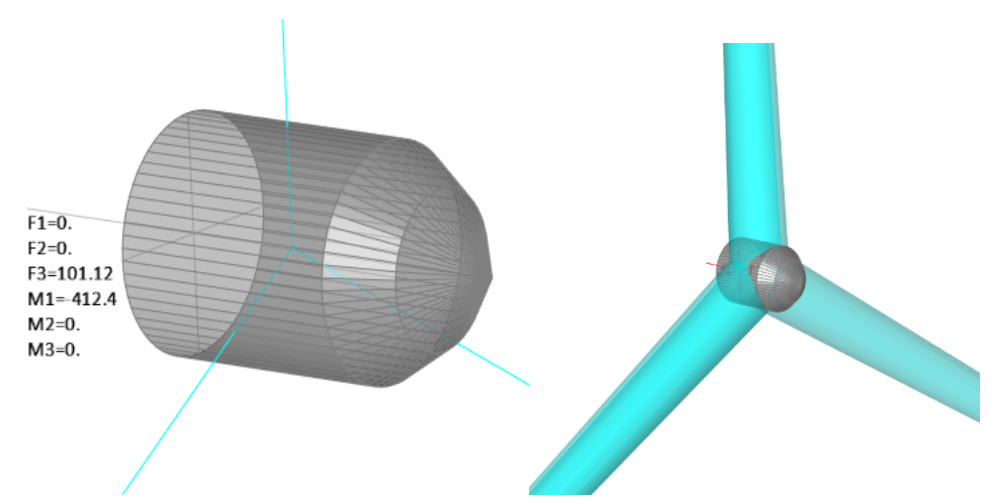

Fig. 13 Definition of a linear link to obtain the dead load of the rotor and the blades.

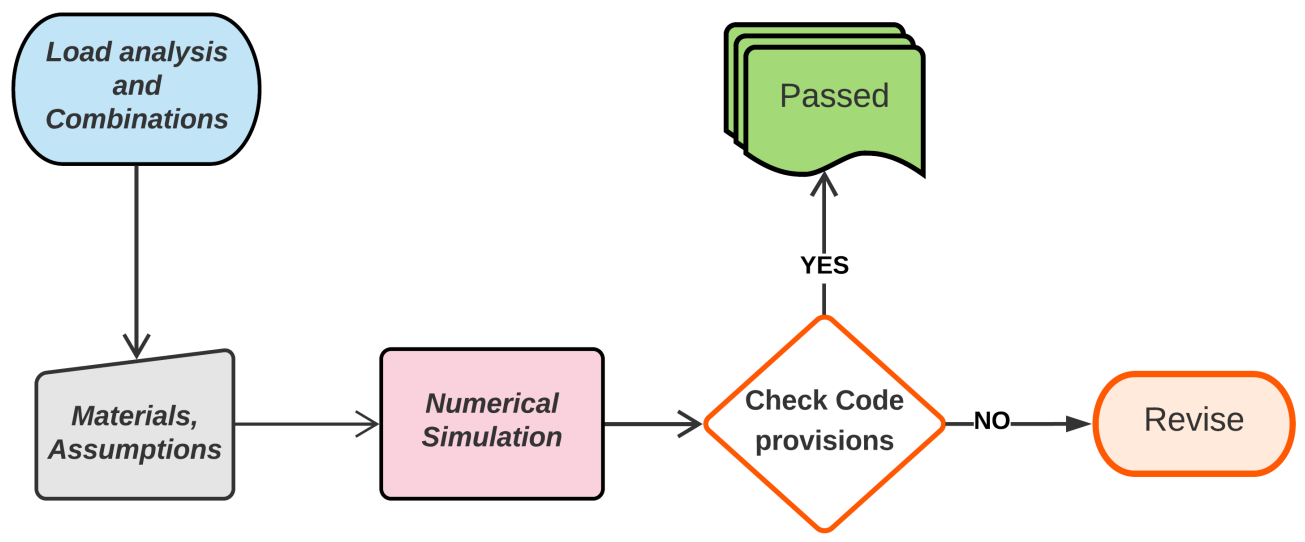

Fig. 14 Flowchart for the analysis and design

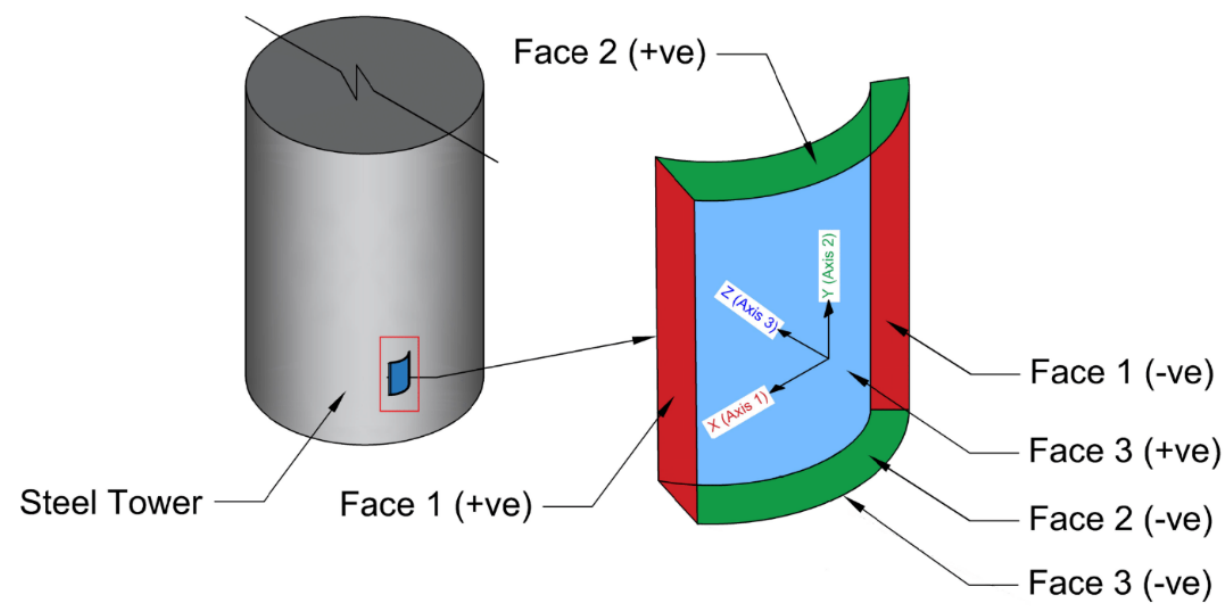

Fig. 15 Shell element showing the faces for stress analysis

\section{Results}

The results in term of stresses, deformations and fudamental periods obtained from the numerical model presented in the previous section are shown here. The stress components Sij (where $i=1$ or 2 , and $\mathrm{j}=1,2$, or 3 ) are stresses that occur on the $i^{\text {th }}$ face of an element in direction j. Direction $j$ refers to the local axis direction of the shell element. The shell element stresses are S11, S22, S12 or S21, S13, and S23. Thus, S11 stresses occur on face 1 of the element (perpendicular to the local axis 1) and are acting in the direction parallel to the local axis 1 (i.e., the stresses act normal to face 1 ). Figure 15 shows examples of each of these basic types of shell stresses. Maximum internal stresses have been reported for the shell elements. 
Table 3

Maximum stress values obtained from different load combina-

\begin{tabular}{|c|c|c|c|c|}
\hline $\begin{array}{l}\text { Load com- } \\
\text { bination }\end{array}$ & $\begin{array}{c}\text { Max S11 } \\
(\mathrm{MPa})\end{array}$ & $\begin{array}{c}\text { Max S22 } \\
(\mathrm{MPa})\end{array}$ & $\begin{array}{c}\text { Max S12 } \\
(\mathrm{MPa})\end{array}$ & $\begin{array}{l}\text { Max S } \\
(\mathrm{MPa})\end{array}$ \\
\hline $\mathrm{LC} 1$ & 93 & 241 & 108 & 145 \\
\hline LC2 & 101 & 197 & 91 & 151 \\
\hline LC3 & 104 & 195 & 73 & 175 \\
\hline $\mathrm{LC} 4$ & 81 & 165 & 76 & 103 \\
\hline LC5 & 67 & 172 & 77 & 103 \\
\hline LC6 & 81 & 165 & 76 & 104 \\
\hline LC7 & 65 & 169 & 79 & 105 \\
\hline
\end{tabular}

The shell stresses in the steel tower should not exceed the minimum yield stress $\left(f_{y}\right)$ to ensure that the design is safe. The in-plane forces/stresses are prominent in the steel towers. The maximum direct shell stresses S11, S22, and shear stress component S12 are also evaluated. The shell stresses from SAP2000 can be directly compared with the allowable stress of the material. Furthermore, Table 3 shows direct and shear stress components for the considered load cases (LC1 to LC7). Maximum stresses are produced from load case 3 (0.9 (DL)-1.35 (WL)-1.6 (TWL)), showing the governing load for the design is the wind load.

The values of the shell stress components are relatively smaller in contrast to the allowable stress values. It is to say that a smaller steel grade, e.g., S355 or S275, can be used instead.
The modal analysis considers the effects of vibration modes higher than the first, thus allowing to consider the irregularities in the dynamic response of the building. For this reason, this particular type of analysis can be used in the presence of irregular structures, in case of both the plan as well as the elevation. In addition, it provides the mode shapes that shows how the structure tends to deform thus depicting the regions of the structures that would witness high stresses. However, comparing the mode shapes and the deformed shapes are important in connection analyses, welding regions, stiffening required, and stresses in the tower. The first three modes of vibration are shown in Figure 16.

The wind turbine manufacturer usually provides the deflection criteria to conduct the analysis, and the applied forces on the tower are also suggested. In this case, the tower's top deflection is calculated by assuming the tower as a fixed cantilever beam at the base. The deflection in top portion of the tower $\delta$ is calculated by applying uniformly distributed load along with the height of the tower. Usually, the calculated deflection in top portion of the tower $\delta$ must be less than $1 \%$ of the total height of the tower (Kumar Sangasuri et al., 2017). The deflection in the tip of the tower can be calculated based on a derived formula for tapered beams/poles for uniformly distributed load according to Eq 11 (McCutcheon, 1983). Substituting all values mentioned in Table 4 in Eq. 13 yields a deflection value $\delta_{\text {tip }} \approx 316 \mathrm{~mm}$.

$$
\delta=\left(\frac{w l^{4}}{8 E I_{A}}\right) \frac{4}{(r-1)^{3}}\left[\frac{\operatorname{In}(r)}{(r-1)}-\frac{\left(11 r^{2}-7 r+2\right)}{6 r^{3}}\right]
$$

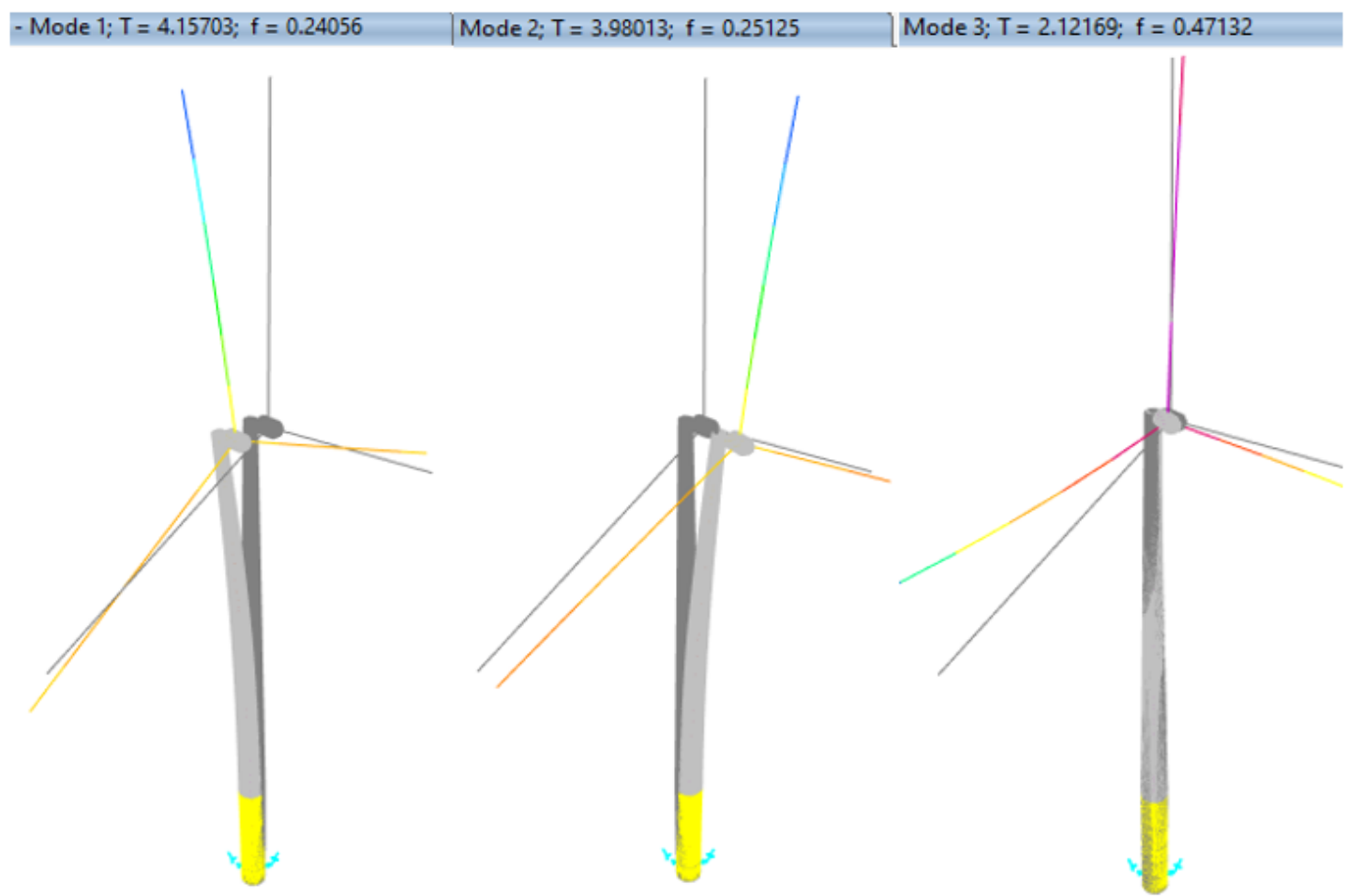

Fig. 16 First three modes of vibrations from modal analysis 
Citation: Naqash, M.T., Aburamadan, M.H., Harireche, O., AlKassem, A., Farooq, Q.U. (2021). The Potential of Wind Energy and Design Implications on Wind Farms in Saudi Arabia. Int. Journal of Renewable Energy Development, 10(4), 839-856, doi: 10.14710/ijred.2021.38226

$\mathrm{P}$ a g e $\mid 852$

Table 4

Parameters for the deflection calculations

\begin{tabular}{ccc}
\hline Variable & Description & Unit \\
\hline $\mathrm{w}$ & Wind load on the tower & $6233(\mathrm{~N} / \mathrm{m})$ \\
$\mathrm{I}$ & $\begin{array}{c}\text { Height of the tower } \\
\text { Young's modulus of the mate- } \\
\text { rial }\end{array}$ & $\begin{array}{c}120(\mathrm{~m}) \\
2.1 \mathrm{E}+11\left(\mathrm{~N} / \mathrm{mm}^{2}\right)\end{array}$ \\
$\mathrm{I}$ & $\begin{array}{c}\text { The inertia of the tower top } \\
\mathrm{r}\end{array}$ & $\begin{array}{c}\text { The ratio of the bottom diam- } \\
\text { eter to the tip diameter } \\
\text { Deflection at the tip of the } \\
\text { tower }\end{array}$ \\
\hline
\end{tabular}

\section{Discussions}

FE analysis (FEA) using SAP2000 is carried out to verify and compare the analytical calculation results. The FEA results vary according to the considered mesh sizes. For comparatively smaller mesh sizes, a closer value of deflection with the analytical calculation is obtained. Table 5 shows the analytical calculation, the FEA, and the deviation values for the deflection at the top of the tower.

The SAP2000 model showed a maximum deflection of $366 \mathrm{~mm}$ at the tip of the tower in the U2 direction, as shown in Figure 17. A slight difference of $7.2 \%$ is observed in the software analysis mesh, that shows more accuracy than the analytical calculation and hence suggesting the high performance of the model.
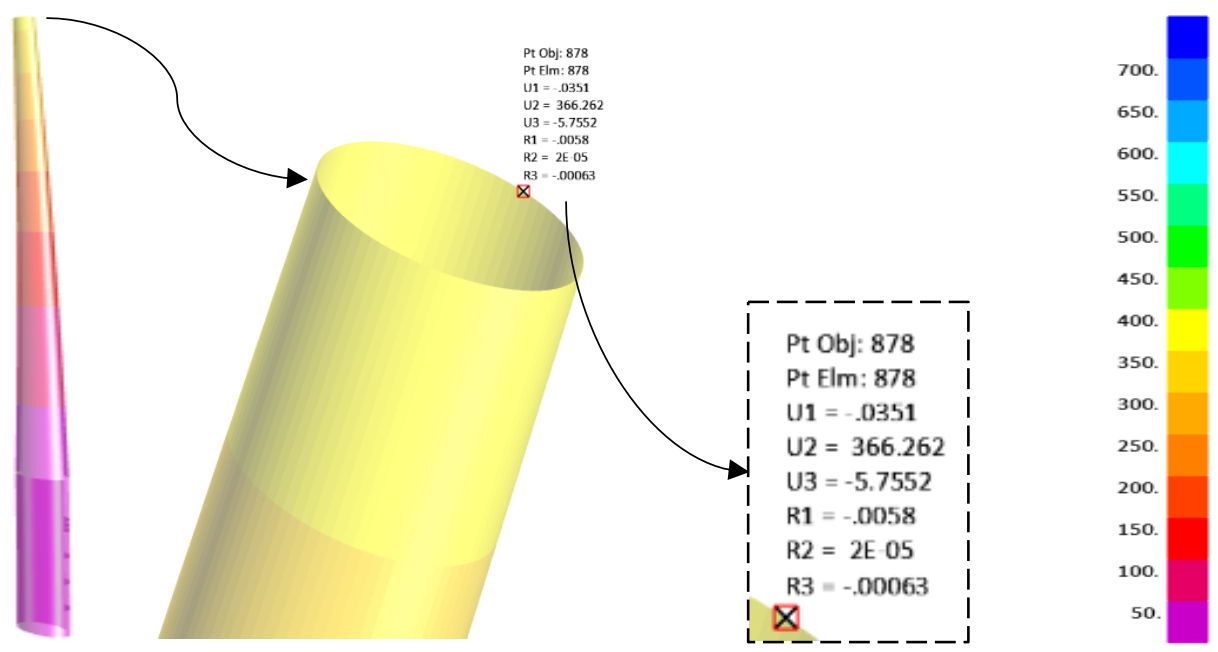

Fig. 17 Maximum deflection at the tip of the tower along with U2

Table 5

Sensitivity analysis considering different mesh size

\begin{tabular}{ccccc}
\hline \multirow{2}{*}{ Mesh type } & Mesh size $(\mathrm{m})$ & \multicolumn{3}{c}{ Tip deflection $(\mathrm{mm})$} \\
\cline { 3 - 5 } & & Analytical & FEA & Deviation \% \\
\hline 1 & none & 316 & 225 & 40 \\
2 & $4 \mathrm{x} 4$ & 316 & 369 & 17 \\
3 & $3 \times 3$ & 316 & 369 & 17 \\
4 & $2 \times 2$ & 316 & 368 & 17 \\
5 & $1 \times 1$ & 316 & 366 & 16 \\
6 & $0.5 \times 0.5$ & 316 & 366 & 16 \\
7 & $0.25 \times 0.25$ & 316 & 366 & 16 \\
\hline
\end{tabular}


Table 6

Obtained deflection from the SAP2000 model under different load cases

\begin{tabular}{ccccccc}
\hline Load Case & Dead (DL) & Wind (WL) & (TWL) & Wave (WvL) & Current (CL) & $\begin{array}{c}\text { Top deflection } \\
(\mathrm{mm})\end{array}$ \\
\hline 1 & 1.4 & 0 & 0 & 0 & 0 & 171 \\
2 & 1.2 & 1.6 & 1.35 & 0 & 0 & 1756 \\
3 & 0.9 & -1.35 & -1.6 & 0 & 0 & 2158 \\
4 & 1 & 1 & 1 & 0 & 0 & 1199 \\
5 & 1 & 0 & 0 & $\mathrm{H}=4, \mathrm{~T}=4$ & $0.6 \mathrm{~m} / \mathrm{sec}$ & 108 \\
6 & 1 & 1 & 1 & $\mathrm{H}=2, \mathrm{~T}=7$ & $0.5 \mathrm{~m} / \mathrm{sec}$ & 1220 \\
7 & 1 & 1 & 0 & $\mathrm{H}=4, \mathrm{~T}=5$ & $0.4 \mathrm{~m} / \mathrm{sec}$ & 266 \\
\hline
\end{tabular}
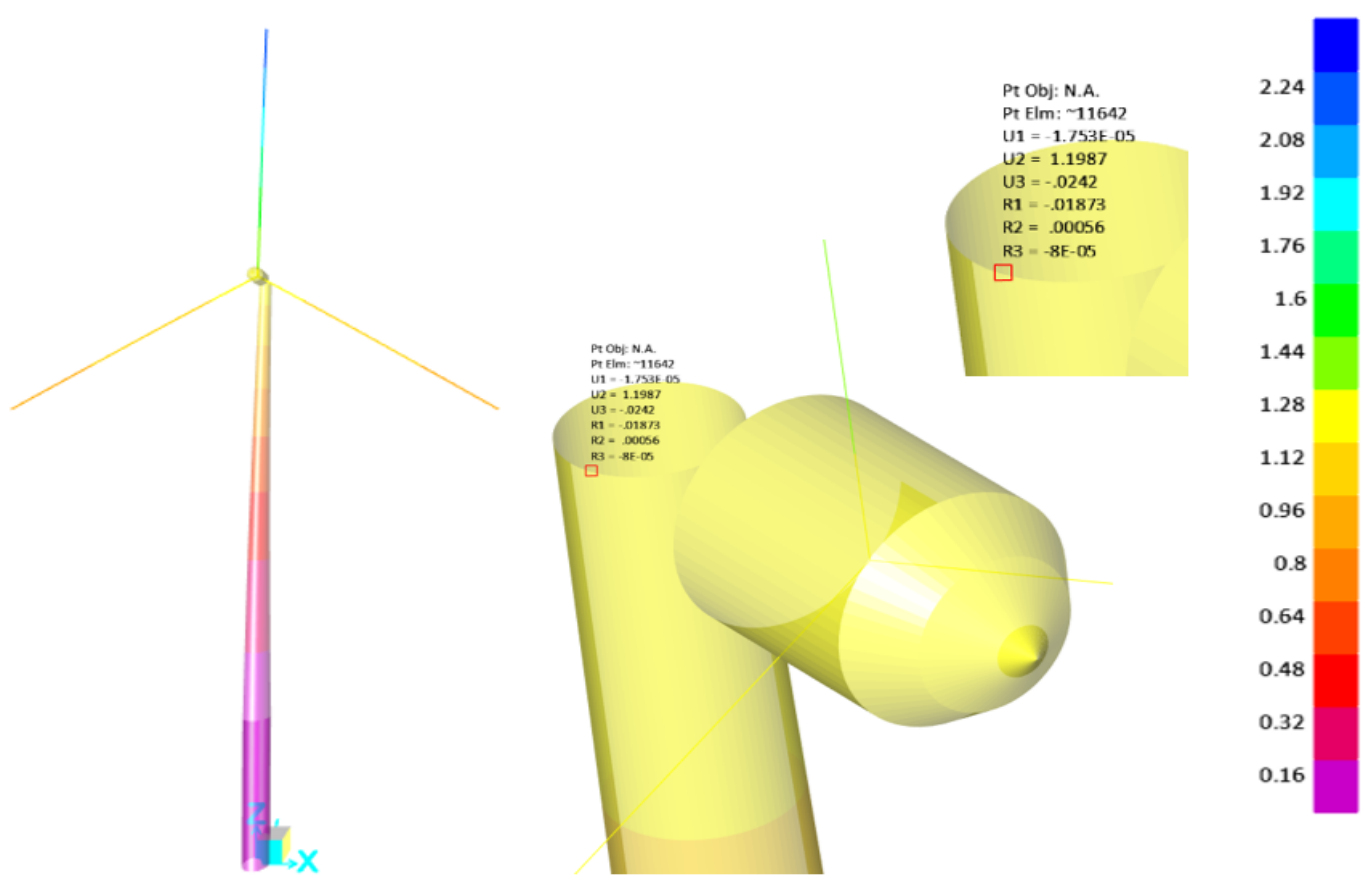

Fig.18 Deflection under load case 4
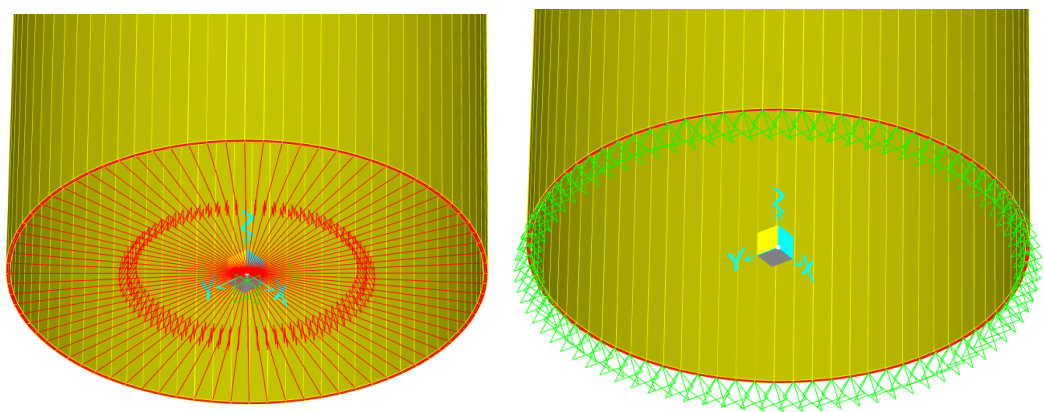

Fig. 19 Base reactions (left) link and (right) support

The previous comparison between the analytical calculation and the FEA is demonstrated to verify the wind load on the steel tower. The tower is subjected to other service loads, including its self-weight, nacelle weight, TWL, wave load, and current load, which significantly increase the tower deflection. According to the deflection criteria given by Equation 13, the calculated results yield a deflection value of $1.19 \mathrm{~m}$ under load case 4, as shown in Figure 18 and Table 6. 
Table 7

\begin{tabular}{cccccccc}
\multicolumn{2}{c}{ Base joint reactions } & \multicolumn{7}{c}{ Joint } & Load case & $\mathrm{F} 1$ & $\mathrm{~F} 2$ & $\mathrm{~F} 3$ & $\mathrm{M} 1$ & $\mathrm{M} 2$ & $\mathrm{M} 3$ \\
\cline { 3 - 8 } & & $\mathrm{kN}$ & $\mathrm{kN}$ & $\mathrm{kN}$ & $\mathrm{kN}-\mathrm{m}$ & $\mathrm{kN}-\mathrm{m}$ & $\mathrm{kN}-\mathrm{m}$ \\
\hline 1 & $\mathrm{LC} 1$ & 0.00 & 0.00 & 9715 & -5662 & 0.00 & 0.00 \\
1 & $\mathrm{LC} 2$ & 0.00 & -1407 & 8338 & 129788 & 0.00 & 0.00 \\
1 & LC3 & 0.00 & 1431 & 6237 & -146618 & 0.00 & 0.00 \\
1 & LC4 & 0.00 & -962 & 6946 & 90064 & 0.00 & 0.00 \\
1 & LC5 & 0.00 & -407 & 6939 & 2465 & 0.00 & 0.00 \\
1 & LC6 & 0.00 & -1086 & 6946 & 91599 & 0.00 & 0.00 \\
1 & LC7 & 0.00 & -740 & 6946 & 31141 & 0.00 & 0.00 \\
\hline
\end{tabular}

It can be observed from the Table 6 that the maximum tip deflection occurs under load case 3. While from load case 7 , it is observed that the maximum tip deflection in the U2 (y) direction is less than the value in both the FEA and analytical calculation. This reduction in deflection is caused due to moment exerted by the rotor on the tower in the opposite wind direction. The foundation analysis calculates the total vertical load, the maximum load on the soil, foundation stiffness values, and foundation overturning and resisting moments. These values are required in order to ensure the foundation design requirements. To simplify the understanding of the base reaction, the base shells are connected with fixed links to a central joint at $\mathrm{X}=0, \mathrm{Y}=0, \mathrm{Z}=0$, as shown in Figure 19. It should be noted that the fixed links method yields the same joints displacements compared to pin supports distributed along the joints of base shells. However, the simplified method is more realistic when designing the foundation for the OWT.

Table 7 shows the base reactions of joint (1) at point 0,0,0 for all the load cases. Load case 3 is the most influential as it generates enormous moment as well lateral and vertical reaction. Nevertheless, the final foundation design depends on local geotechnical conditions such as seabed profile, soil relative density or stiffness, the bearing capacity, and consolidation characteristics of the foundation supporting layers.

\section{Conclusions and future work}

The Kingdom of Saudi Arabia (KSA) is developing rapidly with the Government's vision of working towards a developed nation by 2030 . However, till then, the domestic consumption of energy would unfortunately be almost threefold which necessitates exploring the available renewable energy resources. In view of this, the current paper dealt initially with assessing available wind resources in KSA. This has concerned the maximum wind speed available during the year. For this purpose, seven different locations were chosen located on the Red Sea coastline of KSA. Based on the study conducted, the following conclusions can be drawn:

From the data analysis, maximum wind speed during the year is observed at Al-Wajh region, with a seabed condition suitable for monopile foundations. For this reason,
Al-Wajh was selected as a suitable location for the future development of wind farms. Wind turbine technology has immense fuel-saving potential and, therefore, for the current case from the standpoint of emission analysis for $\mathrm{Al}$ Wajh, it is found that the gross annual GHG emission lowered by about $93 \%$. For the available bathymetry and wind speed, the offshore wind turbine Siemens SWT-3.6-107, which weighs $225 \mathrm{t}$, is deemed as viable machine for the selected site. Given the importance of the structural height and weight of the wind turbine, essential information regarding the design and typical foundation loading was also given.

The proposed supporting structure for the turbine comprises a steel tower, which was modeled as a truncated hollow cone having a diameter of $5 \mathrm{~m}$ and $2.1 \mathrm{~m}$ at base and top, respectively. The tower height $(90 \mathrm{~m})$ of the hub, alongside the transition piece $(30 \mathrm{~m})$, yields an overall height of $120 \mathrm{~m}$ from the mudline.

A basic wind speed of $145 \mathrm{kph}$ with 50 years return period is selected for the tower design, as per Aramco Meteorological and Seismic Design Data. The wave periods are set from 4 to 7 seconds whereas the steel tower is modeled by employing 4 to 7 seconds periods. Using different load combinations as suggested by the design code, the maximum stresses produced from load case 3 depict that the wind loading mainly governs the design. The expected stress magnitude is also within the permissible limits. Furthermore, the self-weight of tower, nacelle weight, TWL, wave load, and current load contribute to a significant increase in the tower deflection. The calculated results give a deflection value of $1.19 \mathrm{~m}$ under loading case 4. For the base structure and the monopile foundation design, load case 3 must be considered as it generates the maximum moment and maximum lateral and vertical reactions. These reactions can be utilized efficaciously to analyze and design appropriate foundation systems considering the details of the seabed profile, the local geotechnical and sea state conditions.

Finally, the local building codes, such as the Saudi Building Code (SBC), are recommended to serve as the primary design basis for OWT support structures. Such codes are required to document and allow related research work to provide valuable data and information such as bathymetry from the shore, seismic intensity, seabed profile, and wind assessments along height. 


\section{Acknowledgment}

The authors acknowledge the financial support of the deanship of research at the Islamic University of Madinah under project no. 11/99.

\section{Notations}

\begin{tabular}{|c|c|c|}
\hline A & $=$ & swept area of a wind turbine $\left(\mathrm{m}^{2}\right)$, \\
\hline API & $=$ & American Petroleum Institute \\
\hline ASCE & & $=\quad$ American Socity of Civil Engineers \\
\hline AWEA & $=$ & American Wind Energy Association \\
\hline $\mathrm{C}_{\mathrm{d}}$ & $=$ & drag coefficient \\
\hline $\begin{array}{l}\mathrm{C}_{\mathrm{p}} \\
\text { efficiency; }\end{array}$ & $=$ & dimensionless parameter known as rotor \\
\hline $\mathrm{D}$ & $=$ & Diameter of the structure \\
\hline $\mathrm{DL}$ & $=$ & Dead load \\
\hline DNV & $=$ & Det Norske Veritas \\
\hline GHG & $=$ & Greenhouse Gas \\
\hline GL & $=$ & Germanischer Lloyd \\
\hline IEC & $=$ & International Electrotechnical Commission \\
\hline $\mathrm{K}_{\mathrm{d}}$ & $=$ & wind directionality factor \\
\hline $\mathrm{K}_{\mathrm{e}}$ & $=$ & ground elevation factor \\
\hline $\mathrm{K}_{\mathrm{z}}$ & $=$ & velocity pressure exposure coefficient \\
\hline $\mathrm{K}_{\mathrm{zt}}$ & $=$ & topographical factor \\
\hline NORSOK & $=$ & norwegian Petroleum Industry \\
\hline $\mathrm{P}$ & $=$ & wind power \\
\hline$P_{D}$ & $=$ & wind power density \\
\hline $\mathrm{q}_{\mathrm{z}}$ & $=$ & velocity pressure at height $\mathrm{z}\left(\mathrm{N} / \mathrm{m}^{2}\right)$ \\
\hline $\mathrm{SBC}$ & $=$ & Saudi Building Code \\
\hline TWL & $=$ & Wind-induced turbine load \\
\hline $\mathrm{U}_{\mathrm{m}}$ & $=$ & mainstream velocity \\
\hline $\mathrm{V}$ & $=$ & basic wind speed \\
\hline $\mathrm{v}$ & $=$ & wind speed at height $\mathrm{H}$ \\
\hline $\mathrm{V}$ & $=$ & viscosity of seawater $\left(1.04 \times 10^{-6}\right)$ \\
\hline Vhub & $=$ & wind speed at $100 \mathrm{~m}$ \\
\hline $\mathrm{V}_{\mathrm{R}}$ & $=$ & wind speed at height $\mathrm{H}_{\mathrm{R}}$ \\
\hline $\mathrm{V}_{\mathrm{z}}$ & $=$ & wind speed at $10 \mathrm{~m}$, which is $40.3 \mathrm{~m} / \mathrm{s}$ \\
\hline WL & $=$ & $\begin{array}{l}\text { direct wind load on the tower EQ is } \\
\text { earthquake load }\end{array}$ \\
\hline $\mathrm{z}$ & $=$ & reference elevation \\
\hline Zhub & $=$ & hub height \\
\hline$B$ & $=$ & friction coefficient \\
\hline$\lambda$ & $=$ & ratio of downwind to upwind velocity \\
\hline $\mathrm{v}$ & $=$ & upwind velocity \\
\hline $\mathrm{v}_{\mathrm{d}}$ & $=$ & downwind velocity \\
\hline$\rho$ & $=$ & represents the air density $\left(\mathrm{kg} / \mathrm{m}^{3}\right)$. \\
\hline$\Sigma\left(\mathrm{C}_{\mathrm{d}} \mathrm{A}\right) \mathrm{I}$ & $=$ & summation of drag areas \\
\hline
\end{tabular}

\section{References}

Al-Douri, Y., Waheeb, S. A., \& Voon, C. H. (2019). Review of the renewable energy outlook in Saudi Arabia. In Journal of Renewable and Sustainable Energy. https://doi.org/10.1063/1.5058184

Allhibi, H., Chowdhury, H., Zaid, M., Loganathan, B., \& Alam, F. (2019). Prospect of wind energy utilization in Saudi Arabia: A review. Energy Procedia. https://doi.org/10.1016/j.egypro.2019.02.184

Recommended Practice for Planning , Designing and Constructing Fixed Offshore Platforms - Working Stress Design API Recommended Practice 2A-WSD (RP 2A-WSD), Api Recommended Practice (2000).

API 2A-WSD. (2014). Planning, Designing, and Constructing Fixed Offshore Platforms-Working Stress Design. In API Recommended Practice.

AWEA. (2011). Wind Energy Industry Manufacturing Supplier Handbook. In Wind Energy Industry Manufacturing
Supplier Handbook.

Baseer, M. A., Meyer, J. P., Rehman, S., \& Alam, M. M. (2017). Wind power characteristics of seven data collection sites in Jubail, Saudi Arabia using Weibull parameters. Renewable Energy. https://doi.org/10.1016/j.renene.2016.10.040

Bruckner, A., Rowlands, G., Riegl, B., Purkis, S., Williams, A., \& Renaud, P. (2011). Atlas of Saudi Arabian Red Sea Marine Habitats.

Demirbas, A., Kabli, M., Alamoudi, R. H., Ahmad, W., \& Basahel, A. (2017). Renewable energy resource facilities in the Kingdom of Saudi Arabia: Prospects, social and political challenges. In Energy Sources, Part B: Economics, Planning and Policy. https://doi.org/10.1080/15567249.2014.996303

Eltamaly, A. M. (2013). Design and implementation of wind energy system in Saudi Arabia. Renewable Energy. https://doi.org/10.1016/j.renene.2013.04.006

Eltamaly, A. M., Addoweesh, K. E., Bawa, U., \& Mohamed, M. A. (2014). Economic Modeling of Hybrid Renewable Energy System: A Case Study in Saudi Arabia. Arabian Journal for Science and Engineering. https://doi.org/10.1007/s13369-014-0945-6

Farooq, Q. U., Naqash, M. T., \& Harireche, O. (2019). A SemiAnalytical Framework for Suction Caisson Installation in Sand. 1-7.

Germanischer Lloyd. (2013). Guideline for the Certification of Condition Monitoring Systems for Wind Turbines. In Germanischer Lloyd Industrial Services GmbH.

Guenoukpati, A., Salami, A. A., Kodjo, M. K., \& Napo, K. (2020). Estimating weibull parameters for wind energy applications using seven numerical methods: Case studies of three coastal sites in West Africa. International Journal of Renewable Energy Development. https://doi.org/10.14710/ijred.9.2.217-226

IEC. (2005). Iec 61400-12-1. International Electrotechnical Commission.

International Eletrotechnical Commision. (2005). IEC 61400-1 Wind Turbines - Part 1: Design requirements. Wind Turbines - Part 1: Design Requirements.

Kadiyala, A., Kommalapati, R., \& Huque, Z. (2017). Characterization of the life cycle greenhouse gas emissions from wind electricity generation systems. International Journal of Energy and Environmental Engineering. https://doi.org/10.1007/s40095-016-0221-5

Kingdom of Saudi Arabia, \& Saudi Vision 2030. (2016). National transformation program 2020. Saudi Vision 2030.

Kumar Sangasuri, S., Srikanth, L., \& Savanur, R. A. (2017). Design and Analysis of a 10Kw Wind Turbine Tower. 12, 93-96.

Langodan, S., Cavaleri, L., Pomaro, A., Portilla, J., Abualnaja, Y., \& Hoteit, I. (2018). Unraveling climatic wind and wave trends in the Red Sea using wave spectra partitioning. Journal of Climate. https://doi.org/10.1175/JCLI-D-170295.1

Langodan, S., Cavaleri, L., Pomaro, A., Vishwanadhapalli, Y., Bertotti, L., \& Hoteit, I. (2017). The climatology of the Red Sea-part 2: the waves. International Journal of Climatology. https://doi.org/10.1002/joc.5101

Luo, F., \& Hong, Y. (2013). Renewable energy systems: advanced conversion technologies and applications. In Taylor \& Frnacis.

Marih, S., Ghomri, L., \& Bekkouche, B. (2020). Evaluation of the wind potential and optimal design of a wind farm in the arzew industrial zone in Western Algeria. International Journal of Renewable Energy Development. https://doi.org/10.14710/ijred.9.2.177-187

McCutcheon, W. J. (1983). Deflections and stresses in circular tapered beams and poles. Civil Engineering for Practicing and Design Engineers.

Mehravar, M., Harireche, O., \& Faramarzi, A. (2016). Evaluation of undrained failure envelopes of caisson foundations 
under combined loading. Applied Ocean Research. https://doi.org/10.1016/j.apor.2016.05.001

Mehravar, M., Harireche, O., Faramarzi, A., \& Alani, A. M. (2017). Modelling the variation of suction pressure during caisson installation in sand using FLAC3D. Ships and Offshore Structures. https://doi.org/10.1080/17445302.2015.1051311

Minimum design loads and associated criteria for buildings and other structures. (2017). In Minimum Design Loads and Associated Criteria for Buildings and Other Structures. https://doi.org/10.1061/9780784414248

Natural Resources Canada. (2013). RETScreen ${ }^{\circledR}$ International. RETScreen Clean Energy Project Analysis Software.

Ralston, D. K., Jiang, H., \& Farrar, J. T. (2013). Waves in the Red Sea: Response to monsoonal and mountain gap winds. Continental Shelf Research. https://doi.org/10.1016/j.csr.2013.05.017

Rehman, S. (2005). Offshore wind power assessment on the east coast of Saudi Arabia. Wind Engineering. https://doi.org/10.1260/030952405775992643

Rehman, S., \& Al-Abbadi, N. M. (2009). Wind power characteristics on the North West coast of Saudi Arabia. Energy and Environment. https://doi.org/10.1260/0958305X.20/21.8/1.1257

Renewable Power Generation Costs in 2019. (n.d.). /Publications/2020/Jun/Renewable-Power-Costs-in-2019. Retrieved February 16, 2021, from /publications/2020/Jun/Renewable-Power-Costs-in-2019

Renewable Resource Atlas. (n.d.). Home | Renewable Resource Atlas. Retrieved February 8, 2021, from https://rratlas.energy.gov.sa/RRMMPublicPortal/?q=en/Ho me

Saigal, R. K., Dolan, D., Der Kiureghian, A., Camp, T., \& Smith, C. E. (2007). Comparison of Design Guidelines for Offshore Wind Energy Systems. https://doi.org/10.4043/18984-ms

Salah, M. M., Abo-khalil, A. G., \& Praveen, R. P. (2019). Wind speed characteristics and energy potential for selected sites in Saudi Arabia. Journal of King Saud University Engineering Sciences, 33(2), 119-128. https://doi.org/10.1016/j.jksues.2019.12.006

Sanchez Gomez, M., \& Lundquist, J. K. (2020). The effect of wind direction shear on turbine performance in a wind farm in central Iowa. Wind Energy Science. https://doi.org/10.5194/wes-5-125-2020

SBC. (2020). Saudi Building Code. https://www.sbc.gov.sa/En/Pages/default.aspx

Shaahid, S. M., Alhems, L. M., \& Rahman, M. K. (2019). Technoeconomic assessment of establishment of wind farms in different Provinces of Saudi Arabia to mitigate future energy challenges. Thermal Science. https://doi.org/10.2298/TSCI171025109S

Siemens Gamesa. (n.d.). DanTysk: offshore wind for Munich I Siemens Gamesa. Retrieved February 6, 2021, from https://www.siemensgamesa.com/en-int/explore/customerreferences/dantysk-offshore-wind-farm

NORSOK: N-003 Actions and action effects, The Norwegian Oil Industry Association (OLF) and Federation of Norwegian Manufacturing Industries (TBL) (2007).

Statistics Time Series. (n.d.). /Statistics/View-Data-byTopic/Capacity-and-Generation/Statistics-Time-Series. Retrieved February 16, 2021, from/Statistics/View-Databy-Topic/Capacity-and-Generation/Statistics-Time-Series

Structural Software for Analysis and Design | SAP2000. (n.d.). Retrieved November 21, 2020, from https://www.csiamerica.com/products/sap2000

Veritas, D. N. (2010). Environmental conditions and environmental loads. Dnv.

You, Z. J., Ji, Z., \& Bai, Y. (2018). Impacts of Storm Wave-induced Coastal Hazards on the Coast of China. Journal of Coastal Research. https://doi.org/10.2112/SI85-166.1 